\title{
Article \\ An Adaptive Sampling Period Approach for Management of IoT Energy Consumption: Case Study Approach
}

\author{
Carlos Rodriguez-Pabon ${ }^{1, *}{ }^{\mathbb{D}}$, Guillermo Riva ${ }^{2}{ }^{(0}$, Carlos Zerbini ${ }^{2}{ }^{\circ}$, Juan Ruiz-Rosero ${ }^{3}{ }^{(}$, \\ Gustavo Ramirez-Gonzalez ${ }^{1}$ iD and Juan Carlos Corrales ${ }^{1}$ (D)
}

check for updates

Citation: Rodriguez-Pabon, C.; Riva, G.; Zerbini, C.; Ruiz-Rosero, J.; Ramirez-Gonzalez, G.; Corrales, J.C. An Adaptive Sampling Period Approach for Management of IoT Energy Consumption: Case Study Approach. Sensors 2022, 22, 1472. https://doi.org/10.3390/s22041472

Academic Editor: Antonio Puliafito

Received: 3 December 2021

Accepted: 27 January 2022

Published: 14 February 2022

Publisher's Note: MDPI stays neutral with regard to jurisdictional claims in published maps and institutional affiliations.

Copyright: (C) 2022 by the authors. Licensee MDPI, Basel, Switzerland. This article is an open access article distributed under the terms and conditions of the Creative Commons Attribution (CC BY) license (https:// creativecommons.org/licenses/by/ $4.0 /)$.
1 Departamento de Telemática, Universidad del Cauca, Calle 5, No. 4-70, Popayan 190002, Colombia; gramirez@unicauca.edu.co (G.R.-G.); jcorral@unicauca.edu.co (J.C.C.)

2 Grupo de Investigacion y Transferencia en Electronica Avanzada (GInTEA), Universidad Tecnologica Nacional, Griva, Cordoba C1041AAJ, Argentina; griva@frc.utn.edu.ar (G.R.); czerbini@frc.utn.edu.ar (C.Z.)

3 Technology Innovation Institute (TII), Abu Dhabi P.O. Box 9639, United Arab Emirates; juanpablo.ruiz@tii.ae

* Correspondence: carlosdr@unicauca.edu.co

\begin{abstract}
The Internet of Things (IoT) opens opportunities to monitor, optimize, and automate processes into the Agricultural Value Chains (AVC). However, challenges remain in terms of energy consumption. In this paper, we assessed the impact of environmental variables in AVC based on the most influential variables. We developed an adaptive sampling period method to save IoT device energy and to maintain the ideal sensing quality based on these variables, particularly for temperature and humidity monitoring. The evaluation on real scenarios (Coffee Crop) shows that the suggested adaptive algorithm can reduce the current consumption up to $11 \%$ compared with a traditional fixed-rate approach, while preserving the accuracy of the data.
\end{abstract}

Keywords: Internet of Things; energy efficiency; agricultural value chain; Colombian coffee

\section{Introduction}

The Internet of Things (IoT) is a technological paradigm consisting of a global network between devices, which can communicate with other objects [1]. IoT opens opportunities beyond optimization and automation of processes when using the collected data. These data are an input for smart systems, which, at the same time, can provide predictions and recommendations [2,3], particularly in monitoring the agricultural value chain (AVC). Therefore, several IoT applications to the agricultural domain have demonstrated that the IoT can support planning or decision-making by owners, managers, and heads of agriculture companies [4]. As a consequence of this support, IoT brings to agriculture some advantages:

- Minimizing the effort required along with different phases of the agricultural value chain; - $\quad$ Enhancing quality of the final product;

- $\quad$ Providing more information to end-user like traceability, product quality, and others;

- Determining the status of the product and its market demand.

However, despite the IoT benefits, there are persisting challenges in energy consumption, communication, storage security, device standardization, and data storage capacity [5-8]. These challenges create difficulties in implementing the monitoring process in AVCs, particularly in the production and post-harvest phases since monitoring variables are under outdoor conditions. Additionally, the storage and transport processes that take place over several days, weeks, or months require efficient monitoring since the environmental conditions necessary to ensure product's quality [9].

These phases have high energy consumption levels on IoT devices, limiting the possibility of recharging them or being connected to the grid or photo-voltaic systems under outdoor conditions. Although the latter is indeed the most used solution [10], these are not 
applicable or represent a high cost, especially for small stakeholder groups. Therefore, managing energy consumption and device efficiency are challenges for supporting IoT-based monitoring at some stages of the AVC.

Low consumption solutions for IoT-based monitoring devices have been classified in different schemes to achieve energy conservation: Sleep/Awake [10,11], querying [12,13], hierarchical processing [14], and routing schemes [15-18]. Some of these schemes employ a few adaptive steps by filtering data, physical reconfiguration, and spatio-temporal correlation [19]. Those schemes are performed over sensor nodes and their environments under a scenario with high device density and servers. Others schemes combine clustering, probabilistic models $[20,21]$, and frequency analysis on sensors [22,23] by implementing an algorithm in the device that allows autonomous management without operating a central node or server. Additionally, [24] uses adaptive schemes to recover data into the context of Bayesian theory; [25] proposes an adaptive sample scheduling mechanism based on signal sparsity and change intensity; [26] proposes three different adaptive sampling rate techniques for industrial wireless sensor networks (IWSNs), which can dynamically estimate the sampling frequency of the collected data; all of them focus on the difference in variation of data between samples.

However, these studies have not presented an energy conservation method in monitoring devices considering the variance of the monitored variables. This paper develops an adaptive sampling period method to save the IoT device energy and maintain the ideal sensing quality based on the variance of variables, particularly for the monitoring of temperature and humidity, which are essential for different stages in coffee AVC. The method was validated in a Case Study in a Colombian Coffee Smart Farm.

The main contributions of this paper include:

- A base method generally applicable to any environmental variable focused on three steps (Capture, analysis, obtain best values);

- An analysis that uses temperature and humidity data, with machine learning tools, finds the proposed equation's best values;

- An evaluation in a real environment of the results generated from data analysis with proposed method.

The remainder of this paper is organized as follows. Section 2 shows the main variables at cultivation production and post production stage; Section 3 presents the monitoring device, current consumption model, and introduces the primary stages through an overview of our approach to the adaptive sampling period; Section 4 describes results; Section 5 presents the discussion; and Section 6 exposes conclusions and future work.

\section{Influence of Variables at Cultivation Production and Post-Production Stage}

Table 1 shows articles that have worked on the study of environmental variables that affect agricultural products at the pre-production stage of the value chain, such as [27], who expose weather variables, including rainfall, temperature, humidity, and wind are tied with agriculture production, as well as [28], implement a greenhouse production environment measurement and control system, offers an excellent growth condition based on monitoring of temperature and humidity.

Furthermore, at production stage articles [29] identifies changes due to temperature and relative humidity in flavor, texture, shelf life, nutritional attributes, aroma, among others, once the product harvest occurs for different fresh fruits and vegetables. Same as [30] suggests permanent monitoring of crops to minimize risks to face dangerous levels of temperature and humidity.

In the production stage, specifically after harvest, variables, such as concentration of oxygen, light levels, and gases [31,32], are relevant because they generate decomposition of products or materials; however, variables such as temperature and humidity continue to be necessary. 
Additionally, several works focus on cold chains in the transport phases, which are transverse to the products in agricultural value chains which represent the main fruits and vegetables susceptible to chill injury variables [31].

In general, throughout the value chain, it is essential to emphasize that the most critical variables are temperature and humidity, so they have to be at limited levels. As evidenced in articles [32,33].

Table 1. Documents related to environmental variables in the agricultural value chain.

\begin{tabular}{lll}
\hline Ref. & AVC Stage & Environment Variables \\
\hline$[28]$ & Pre production & Temperature, Relative humidity \\
\hline$[29]$ & Production & Temperature, Relative humidity \\
\hline$[34]$ & Production, Post Production & Temperature, humidity \\
\hline$[30]$ & Pre production, production & Temperature, humidity \\
\hline$[27]$ & Pre production & Rainfall, temperature, humidity and wind \\
\hline$[35]$ & Post production & Temperature, humidity \\
\hline$[31]$ & Transport & Temperature, Humidity, environmental gases \\
\hline$[36]$ & Distribution & Temperature, Humidity \\
\hline$[37]$ & Post production, distribution & Temperature \\
\hline$[32]$ & Post production, distribution & Temperature, humidity, oxygen concentration \\
\hline$[38]$ & All Stages & Temperature \\
\hline$[33]$ & All Stages & Humidity \\
\hline
\end{tabular}

\section{Energy Consumption Management Approach}

This section describes the device selected and current consumption model and introduces the primary stages through an adaptive sampling period method overview.

\subsection{Monitoring Device}

Figure 1 shows the CSCG Tag [39]. It is an IoT solution with an internal processor $32 \mathrm{MHz}$ MCU w/ 512KB internal flash and audio support, which combines features and functions needed for all 2.4 GHz IoT standards into a single SoC (System on Chip). Additionally, it has a holder to install a coin-type battery, a programming port, and radio communication hardware; also, it has ambient light, temperature, humidity, and shock/tilt sensors. The light sensor measures visible light intensity. Simultaneously, humidity and temperature sensors provide high accuracy measurements with very low current consumption in an ultra-compact WLCSP (Wafer Level Chip Scale Package).

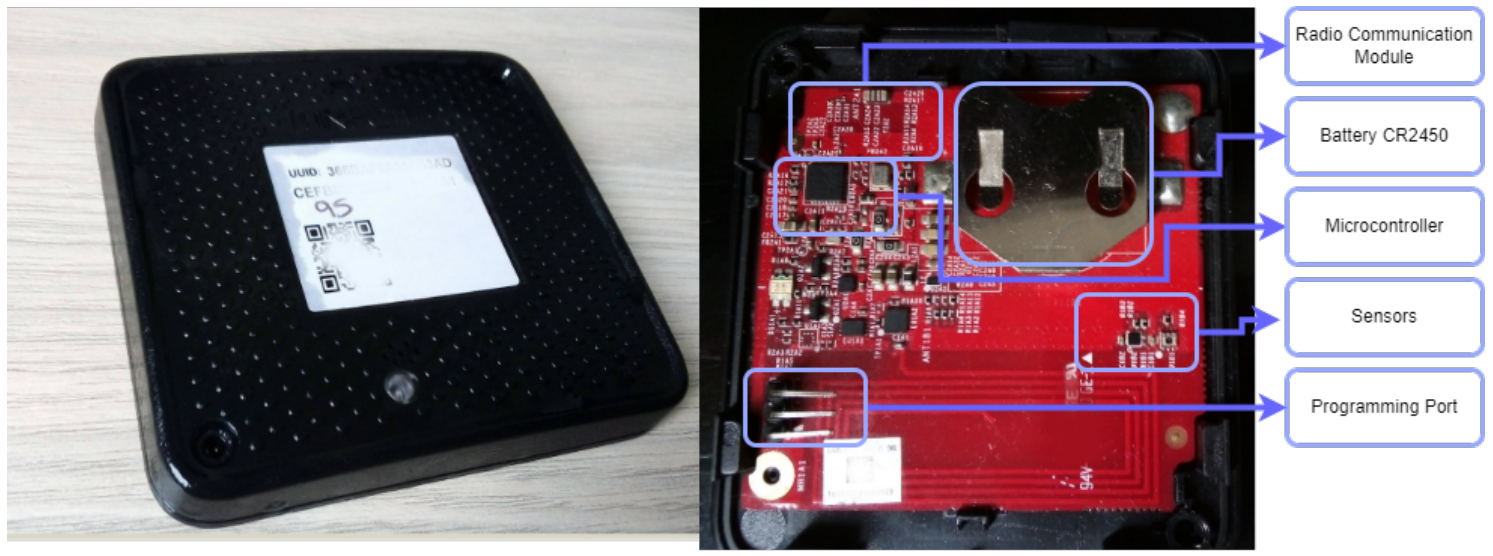

Figure 1. IoT Monitoring CSCG Tag. 


\subsection{Architecture}

The IoT devices selected in this study are part of the Smart Farming System based on a three-layered architecture [40]. Figure 2 shows the device belongs to the perception layer located on the farm; they send monitored variables and have communication with a higher layer (Edge Layer) which processes the data and can manage the devices if required. The CSCG label was programmed under C language, the communication configured with IEEE 802.15.4 [41] protocol, conceives a communication range of $10 \mathrm{~m}$ with a transfer speed of $250 \mathrm{kbit} / \mathrm{s}$. The devices at the edge layer also receive data from the perception layer, process them, and send it to the servers for further analysis.

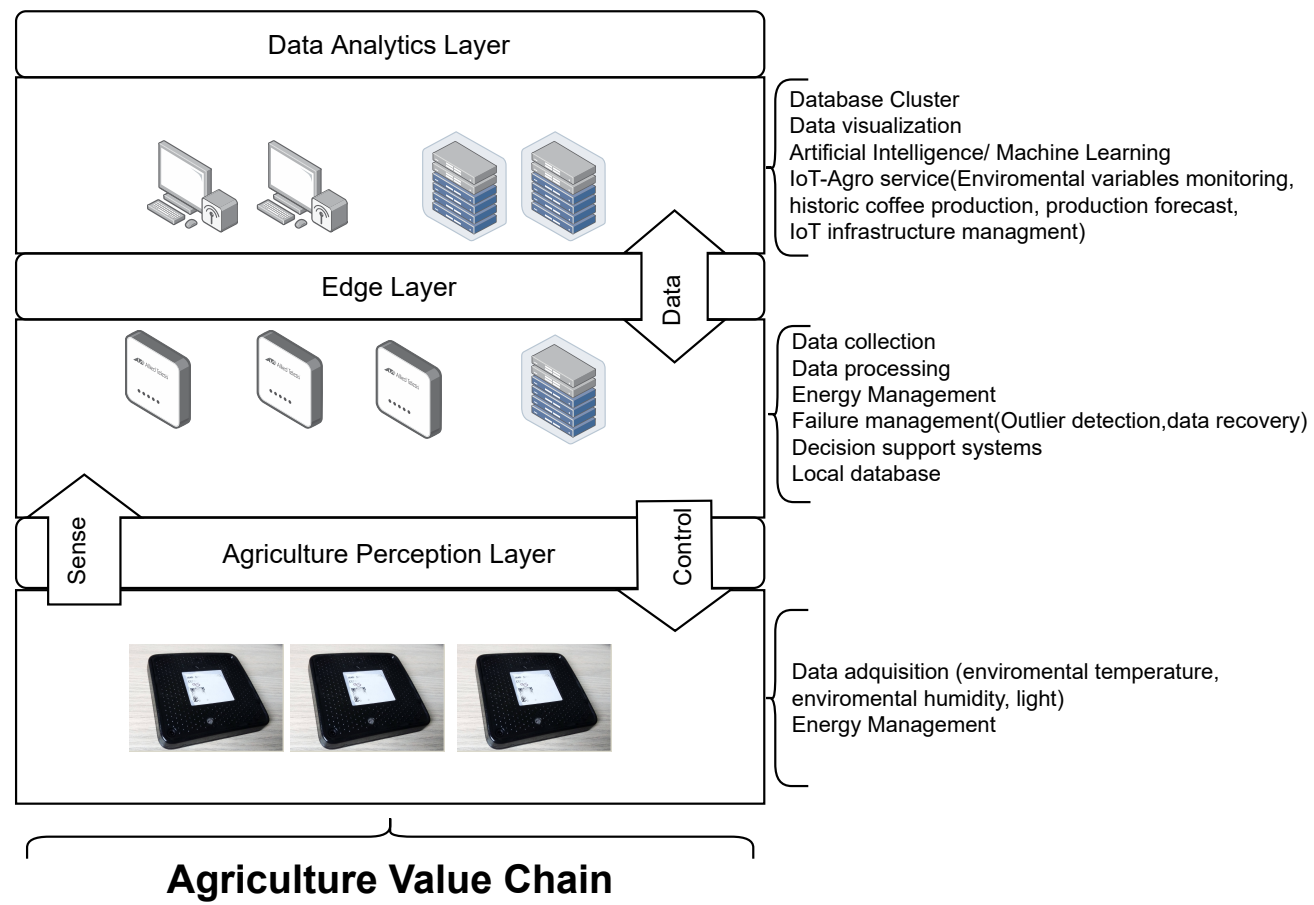

Figure 2. Smart Farming System Architecture.

\subsection{Current Consumption}

The CSCG tag stays most of the time in low power mode because the minimum sampling periods for environmental variables are in the order of seconds. However, some functions are activated periodically to maintain the state machine and perform sensor reading tasks, data transmission, and commands reception by wireless protocol.

For current consumption analysis, we use the Otii Arc DC Power Analyzer Data Logger device [42] set constant voltage source. Figure 3 shows the device's current consumption configured for data transmission every minute. The device wakes up every $30 \mathrm{~s}$ to update the state machine. Additionally, it shows power-up intervals where peripherals, radio communication, state machine, and configured sensors take about $4 \mathrm{~s}$.

Figure 4 focuses on current consumption when the device is awake; there are five stages, state machine update, sensor readout, transmission, time for reception of configuration commands, and time when the device prepares to go to sleep. 


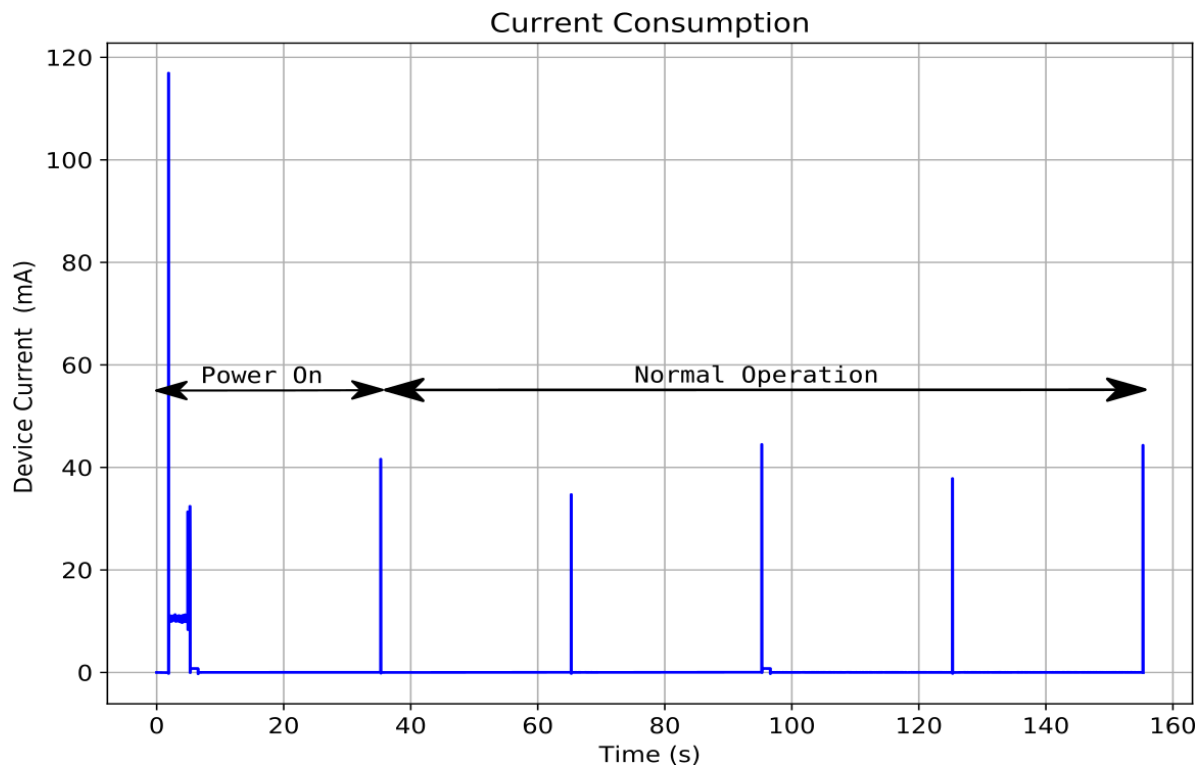

Figure 3. Current consumption on CSCG Tag.

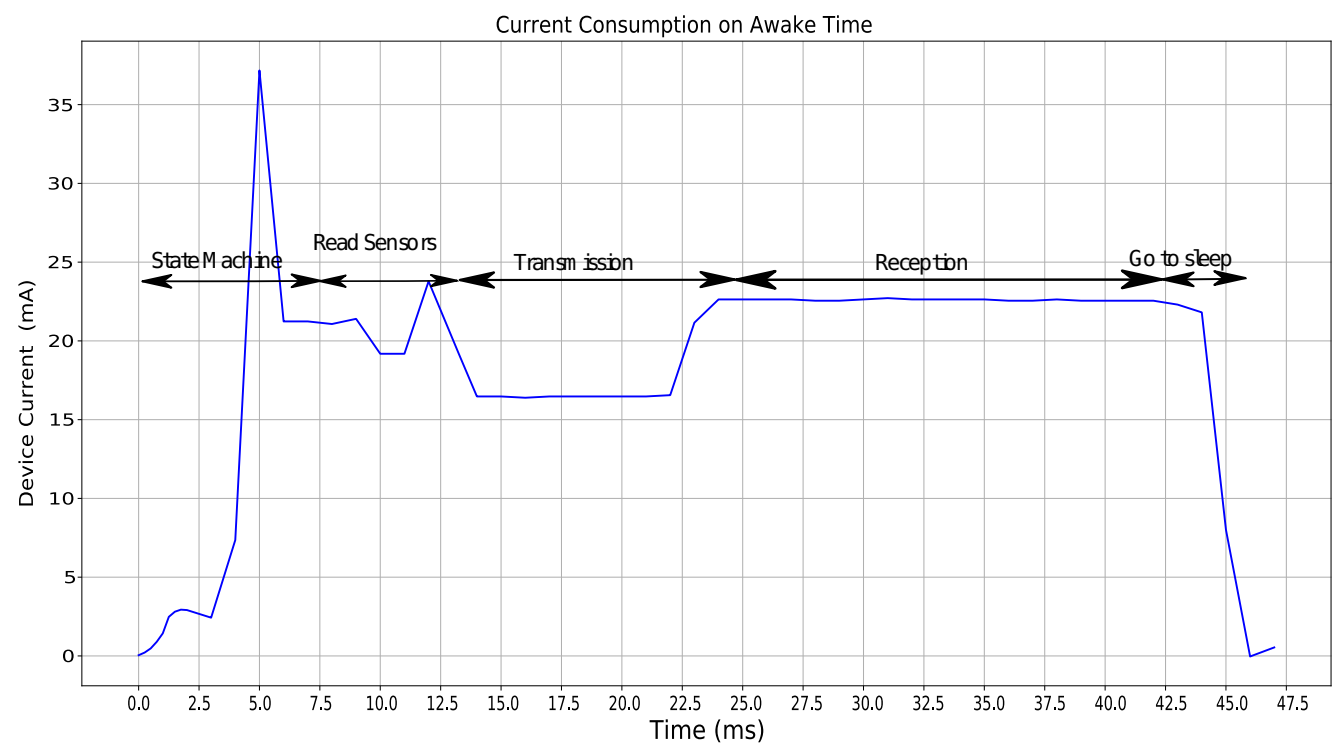

Figure 4. Current consumption during awake time.

Equation (1) shows average total current consumed by an IoT device defined as the sum of current consumption multiplied by its duration divided by total time equation.

$$
I_{\text {avg }}=\frac{I_{\text {awake }} * T_{\text {arwake }}+I_{\text {sleep }} * T_{\text {sleep }}}{T_{\text {total }}}
$$

where:

- $I_{\text {avg }}$ : average current consumption $(\mu \mathrm{A})$;

- $I_{\text {awake }}$ : current consumption when device is awake $(\mu \mathrm{A})$;

- $T_{\text {awake }}$ : awake time (ms);

- $I_{\text {sleep }}$ : current consumption when the device is on sleep mode $(\mu \mathrm{A})$;

- $T_{\text {sleep }}$ : sleep time (ms);

- $T_{\text {total }}$ : total time (ms).

Following the power consumption during active periods is:

$$
I_{\text {awake }} * T_{\text {awake }}=\lambda * I_{s m} * T_{s m} * S T+I_{s n} * T_{s n} * S T+I_{t x} * T_{t x}+I_{r x} * T_{r x}+I_{s l} * T_{s l} * S T
$$


where:

- $\quad S T$ : times per period of time;

- $\lambda$ : number of times the status machine is updated per minute;

- $\quad I_{s m}$ : current consumption when device is updating the state machine $(\mu \mathrm{A})$;

- $T_{s m}$ : state machine time (ms);

- $\quad I_{s n}$ : current consumption when device is reading sensors $(\mu \mathrm{A})$;

- $T_{s n}$ : reading sensors time (ms);

- $I_{t x}$ : current consumption when device is transmitting data $(\mu \mathrm{A})$;

- $T_{t x}$ : transmission time (ms);

- $I_{r x}$ : current consumption when device is on reception mode $(\mu \mathrm{A})$;

- $T_{t x}$ : reception time (ms);

- $\quad I_{s l}$ : current consumption when device is going to sleep mode $(\mu \mathrm{A})$;

- $T_{s l}$ : to go sleep mode time (ms).

The Equation (2) shows ST is a variable without units that describes the number of times that each stage is executed over the total time; this means that in a period of $8 \mathrm{~min}$, the reading of sensors is performed eight times, during this time the data are stored. When the time is up, the data from sensors are averaged and transmitted, and reception of acknowledge and configuration commands from the central node is expected. Therefore, transmission and reception only take place once in a period.

Following we define: $T_{\text {sleep }}$

$$
T_{\text {sleep }}=\left(T_{\text {total }}-T_{\text {awake }}\right)
$$

where $T_{\text {total }}$ : corresponds to total time in ms defined as:

$$
T_{\text {total }}=60 * 1000 * S T
$$

Replacing $T_{\text {awake }}$

$$
T_{\text {awake }}=\lambda * T_{s m} * S T+T_{s n} * S T+T_{t x}+T_{r x}+I_{s l} * T_{s l}
$$

Finally, the equation of current consumption is:

$$
\begin{array}{r}
I_{\text {avg }}=\frac{\lambda * I_{s m} * T_{s m} * S T+I_{s n} * T_{s n} * S T+I_{t x} * T_{t x}+I_{r x} * T_{r x}+I_{s l} * T_{s l}}{60 * 1000 * S T} \\
+\frac{\left(I_{\text {sleep }} *\left(\left(60000-\lambda * T_{s m}\right) * S T-\left(T_{t x}+T_{r x}\right)\right)\right)}{60 * 1000 * S T}
\end{array}
$$

Equation (6) allows determining the average current consumption related to sampling interval and the monitoring device's performance. Figure 5 shows sampling interval between 1 to $30 \mathrm{~min}$ for $\lambda=2$.

After developing our energy consumption model for the selected device, the following section introduces our energy consumption optimization management through an overview of the method and a brief description of the algorithm used. 


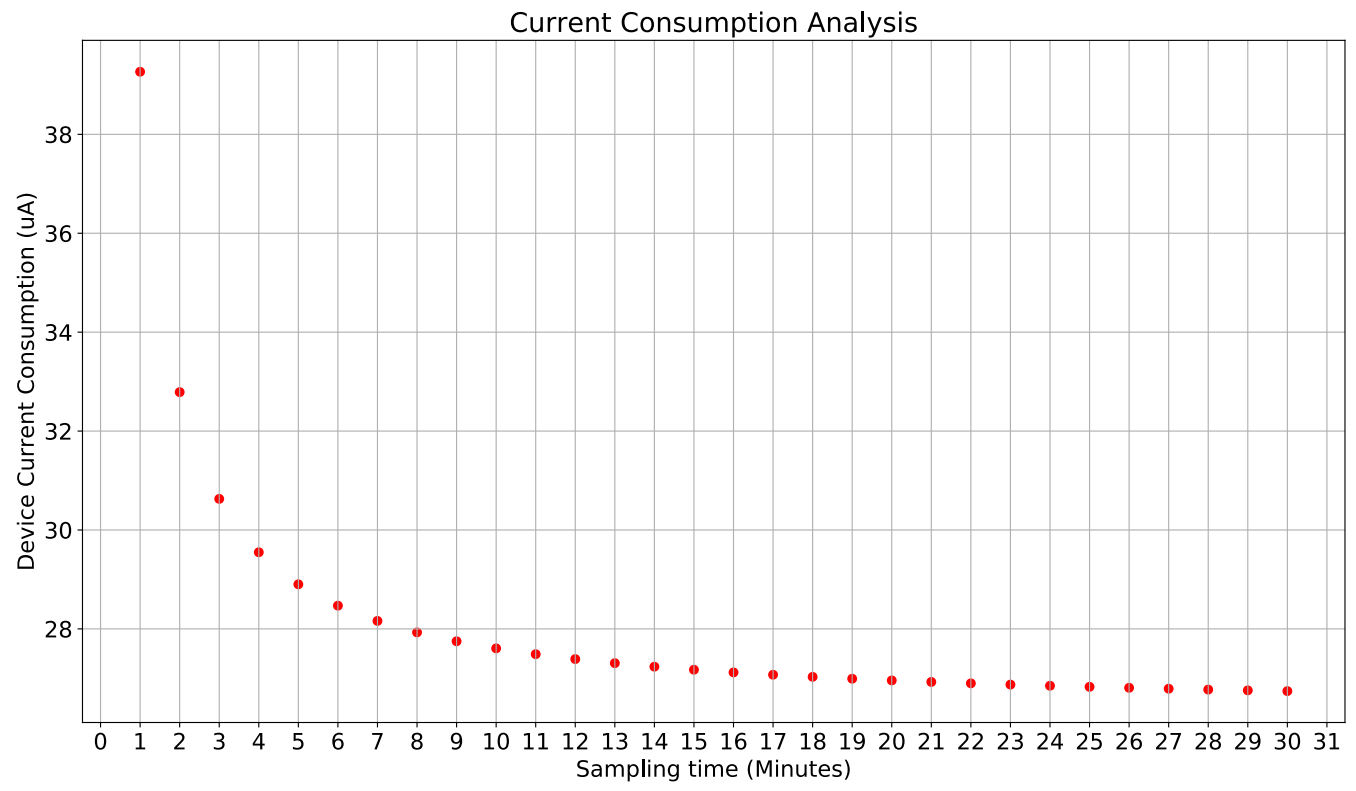

Figure 5. Current consumption vs. sampling interval.

\subsection{System Overview}

Figure 6 shows an method overview for managing optimize energy consumption in IoT monitoring systems based on adaptive sampling period. Overall, the proposed method includes three stages.

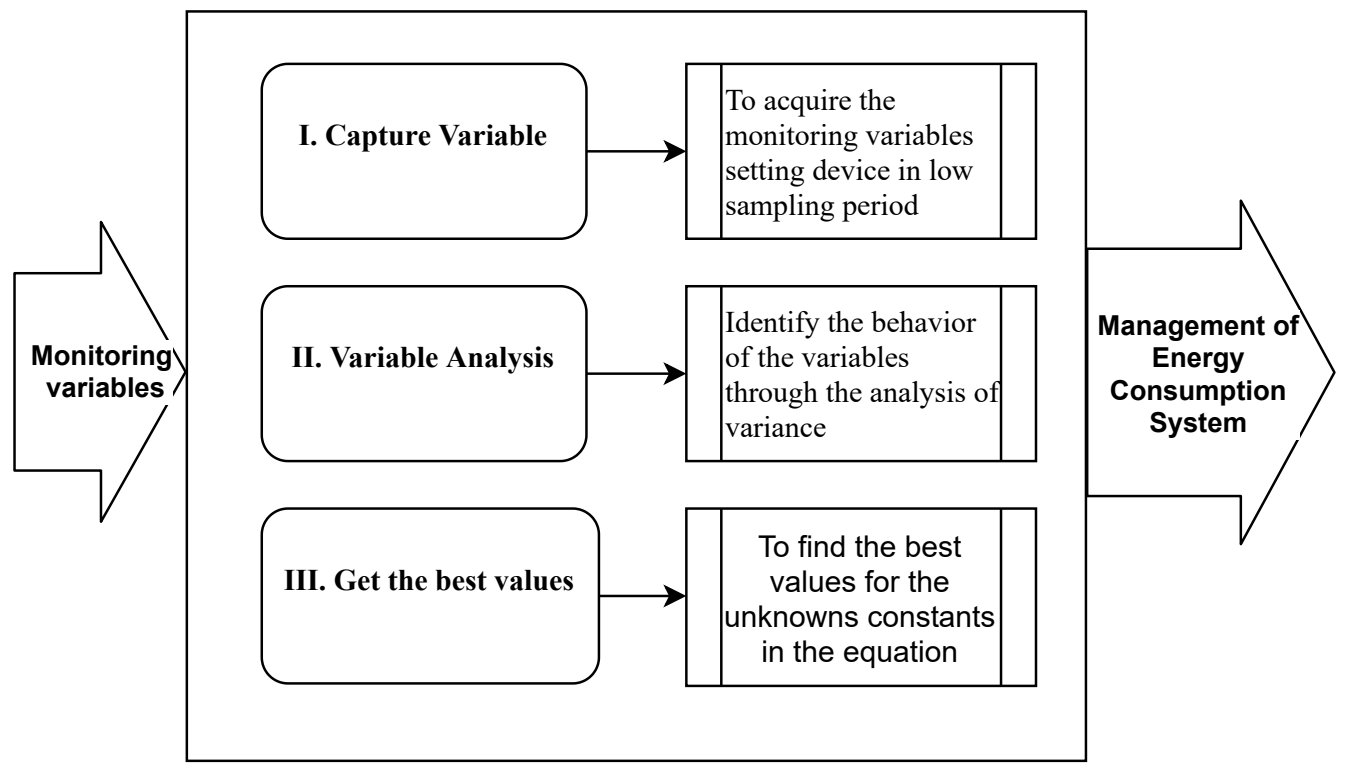

Figure 6. Method for management of energy consumption.

- $\quad$ Stage I: the environment variables are the input of this stage; this shows the variable behavior in the environment where it is installed; the goal is to acquire the follow-up variables with the minimum sampling period allowed. With this, it is possible to identify if a variable presents an excessive sampling because its change is not so fast or requires a lower sampling period. The output of this stage is the monitoring variables dataset.

- $\quad$ Stage II: the variable analysis receives captured data and is responsible for analyzing the variables' behavior over time-based mainly on the data variance, determining the most appropriate variable to manage energy consumption. The output of this stage is the monitoring variable selected. 
- $\quad$ Stage III: starts from a linear equation as a variance function and two unknown constants $(\alpha, \beta)$; At this point, an iterative process is proposed that begins by defining a combination of values in a defined range, from which a pair of them is taken to test them on the dataset and obtain the evaluation metrics, the iterative process ended when all combinations of values on dataset were tested. Finally, the pair of values that generate the minimum value of the sum of evaluated metrics is selected. Figure 7 summarizes the algorithm flow.

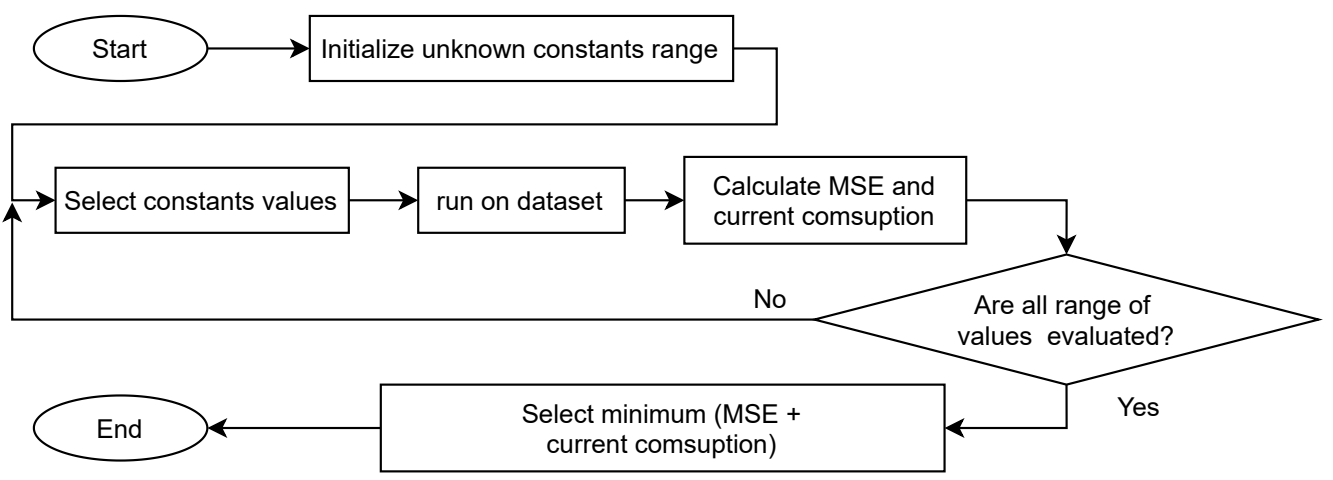

Figure 7. Flow chart to find the best constant values.

In this study, the evaluation metrics are current consumption equation found in Section 3.3 and mean square error (MSE) defined as:

$$
M S E=\frac{1}{n} \sum_{t=1}^{n} e_{t}^{2}
$$

where:

$$
\begin{gathered}
\qquad e_{t}^{2}=\left(X_{i}-\hat{X}_{i}\right)^{2} \\
X_{i} \rightarrow \text { Vector of observed values of the variable being predicted } \\
\hat{X}_{i} \rightarrow \text { Vector of predicted values }
\end{gathered}
$$

With the constant equation values, a monitoring device is programmed which manage the data transmission periods; therefore, the variables and their performance are evaluated concerning fixed sampling techniques.

\section{Results}

\subsection{Stage I-Data Acquisition}

Supracafe [43] is a company that has modelled each stage of the coffee value chain; Figure 8 briefly shows from crop to export stages using Business Process Model and Notation(BPMN); however, we focus only on two value chain stages highlighted in red. For Crop, the inputs at this stage are coffee seeds. This stage is associated with four roles of coffee growers at the Crop beginning: Germinator, Seedling, Planting, and Growth. It can take between eight months and two years. It is a stage that takes the longest of the entire value chain. Then, the harvest stage begins, accompanied by transport phases. Coffee beans go through transformation processes, from cherry coffee to parchment coffee and wet to dry coffee. Coffee is classified and threshed in the storage stage, turning into green coffee; this process can take between two weeks and six months. The next stages are land or ship transportation, sale, and export until roasting, where the coffee already acquires all its properties and is ready for consumption. The detailed BPMN-based coffee value chain is available on the following repository [44]. 


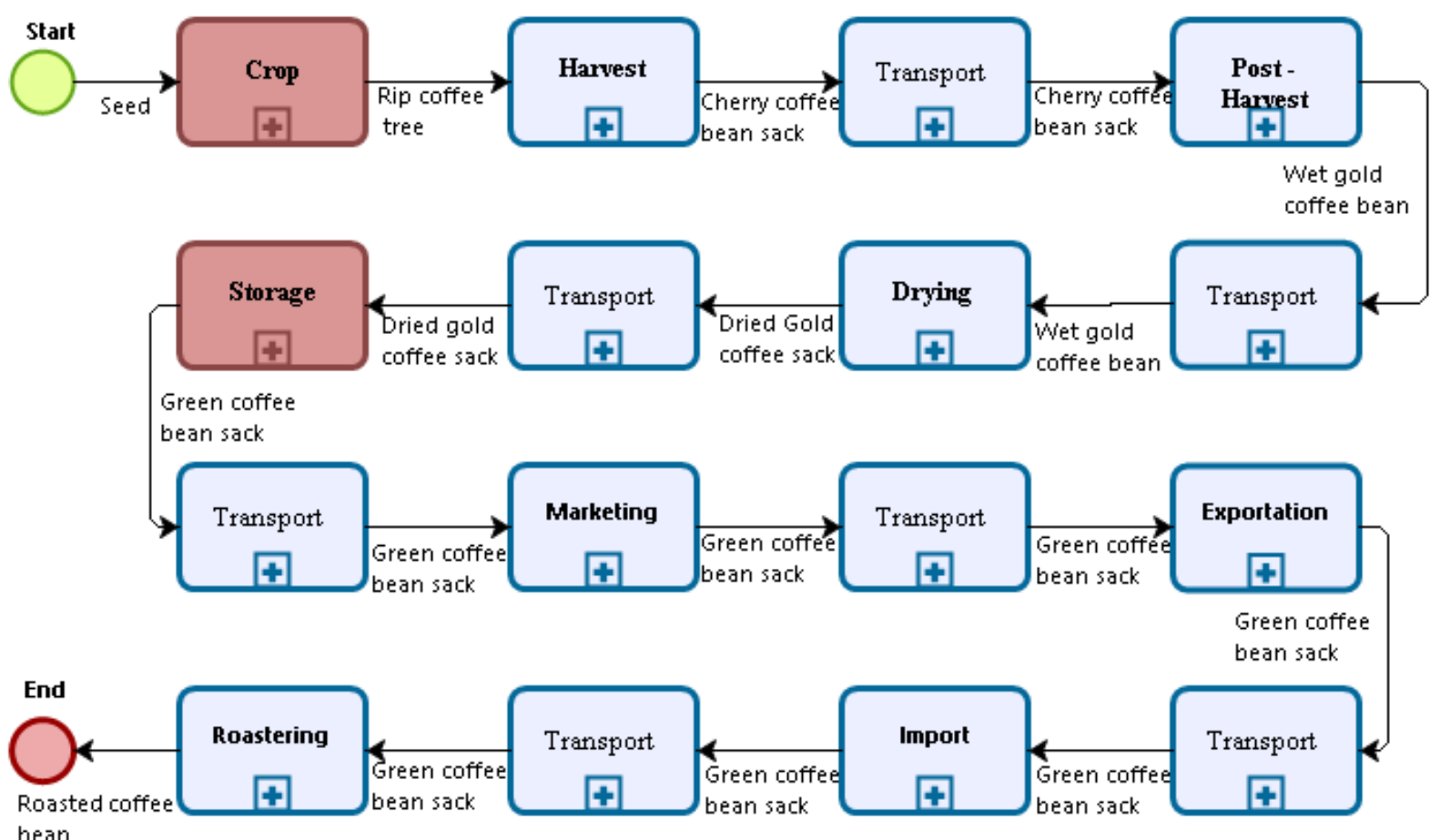

Figure 8. BPMN Coffee value chain.

The study case was in the crop and storage stages of the coffee value chain; with IoT monitoring devices installed in the coffee farm "Los Naranjos" we validated the model. This farm belongs to Supracafé, located in La Venta district, in the municipality of Cajibio, Cauca $\left(21-35^{\prime} 08^{\prime \prime} \mathrm{N}, 76-32^{\prime} 53^{\prime \prime} \mathrm{W}\right)$.

For the crop stage, the devices configured to the lowest sampling period ( $1 \mathrm{~min})$, three devices in each plot, located at different heights on the tree see Figure 9 and three lots were monitored. The monitoring process was carried out during March, April, June, July, August, and September 2020.

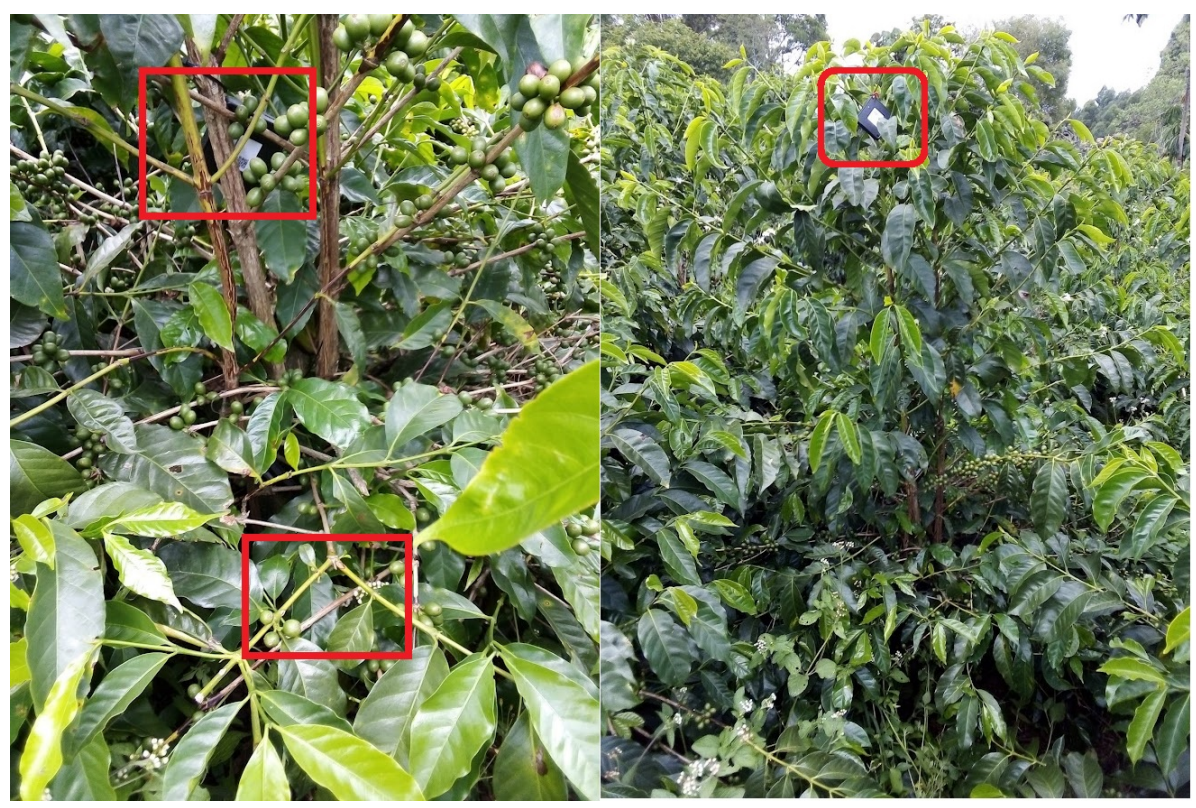

Figure 9. Installation of devices on Coffee plots.

Figure 10 presents the variations in temperature and humidity $(\mathrm{RH})$ in the selected days. The analysis considered days that showed different rainy, sunny, and cloudy climatic 
conditions. The graph presents changes in temperature with minimum values of $9.42{ }^{\circ} \mathrm{C}$ and a maximum value of $35.62^{\circ} \mathrm{C}$. In turn, there are variations in humidity with minimum values of $21.7 \% \mathrm{RH}$ and a maximum value of $100 \% \mathrm{RH}$.
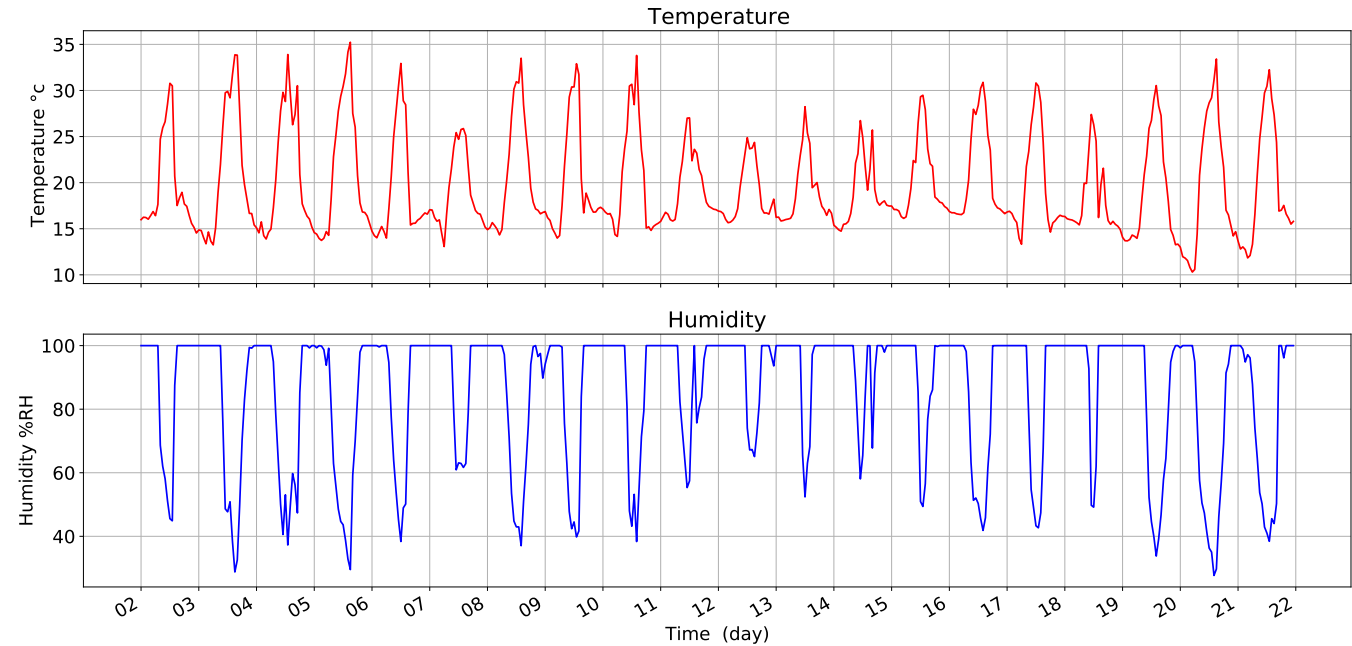

Figure 10. Temperature and humidity at Coffee farm.

\subsection{Stage II-Variable Analysis}

In this section, we used machine learning tools available in Python; from the collected data analysis by sensors, the main parameters are variable's variance and error for different fixed sampling intervals.

\subsubsection{Temperature Analysis}

Figure 11 presents the data captured (red line) and values simulation when changing the sampling period to different fixed values; these values are obtained from an average data real captured. The error presents data sampled every minute. Similarly, an attenuation is observed in the variable's peak values concerning the original sampling period.

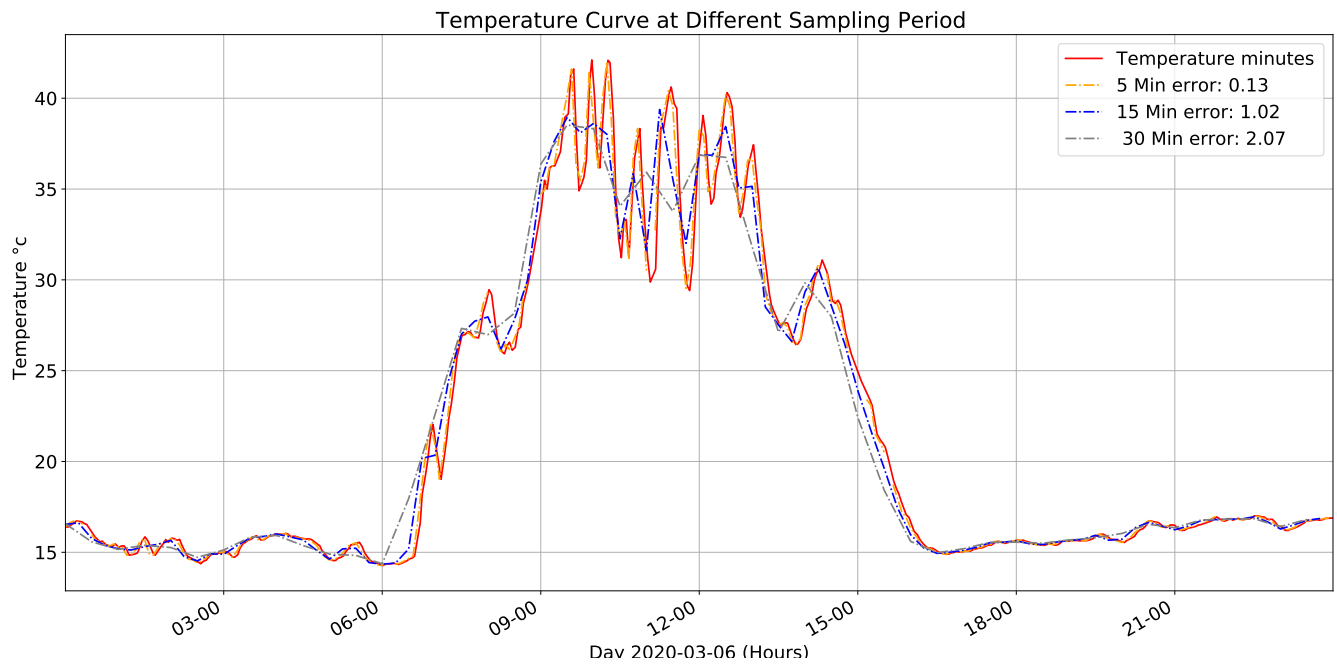

Figure 11. Temperature for different sampling times.

Figure 12 presents variance calculation for fixed sampling periods for the data of every minute. The highest variations in the values are between 9 and $14 \mathrm{~h}$; likewise, there are some minor peaks between 6 to $9 \mathrm{~h}$ and 14 to $17 \mathrm{~h}$ of the day, although previous results correspond to March 06, this behavior is similar for different days under different climatic conditions. 


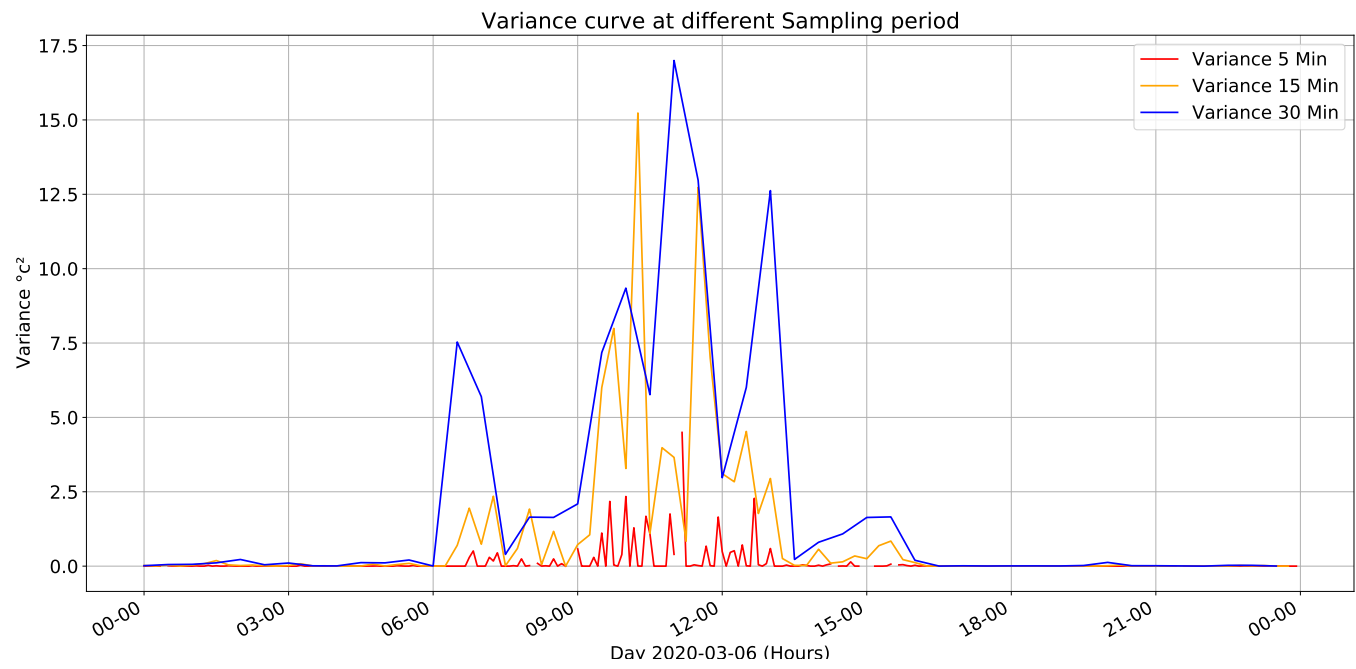

Figure 12. Temperature's variance for different sampling times.

\subsubsection{Humidity Analysis}

Figure 13 presents captured data (red line) and a humidity simulation from the values sampled every minute when changing the sampling period to different fixed values and the error it presents concerning the data sampled every minute. It also shows that the selected sampling period's error is more significant for those given in the temperature graph and saturation in the humidity percentage at night.

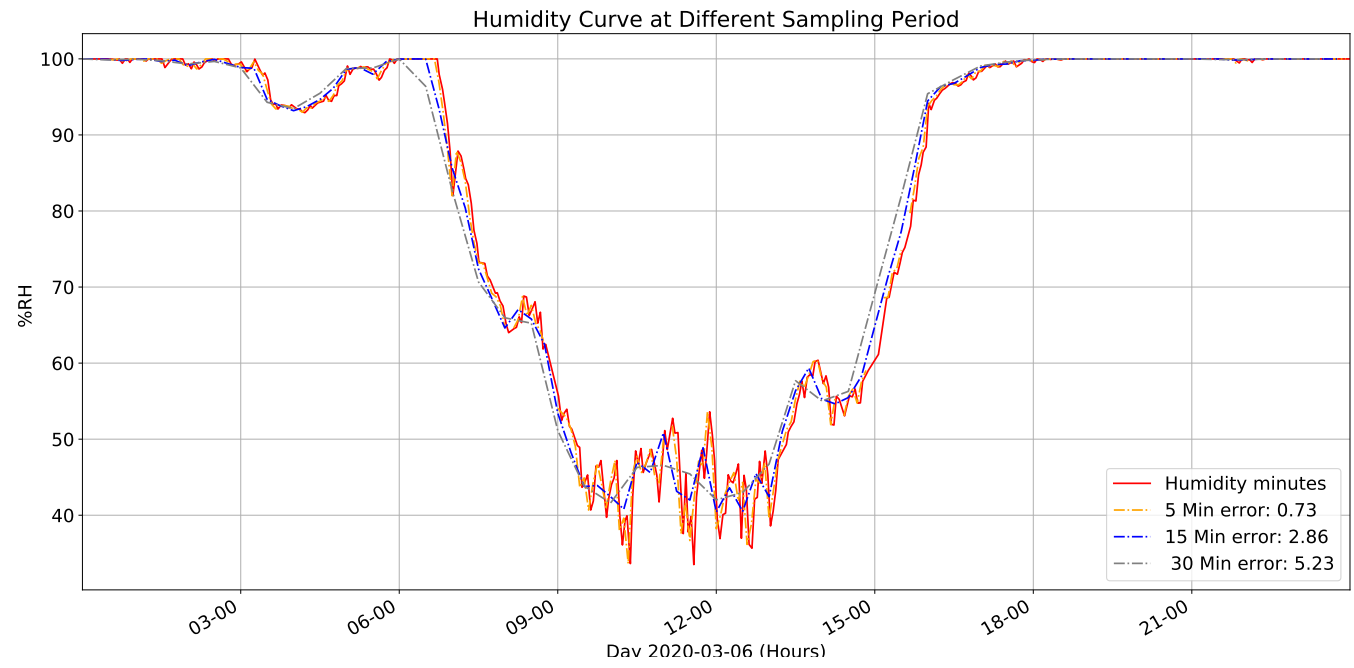

Figure 13. Humidity for different sampling times.

Figure 14 presents variance for fixed sampling periods to data sampled every minute. Compared with previous figure, it presents substantial variations between 8 and $20 \mathrm{~h}$ with a maximum peak of $29 \%$ at $11: 30$ in the morning. However, variations are much higher than those managed in temperature, making it more relevant for the management system approach.

The previous data corresponds to one day; therefore, we made the same analysis for selected days group.

Figure 15 shows variance distribution to selected days, revealing a recurring variation between 7:00 and 11:30 h, with a peak of variation at 8:30, as well as a second minor peak between 13:30 and 17:00 $\mathrm{h}$. Therefore, based on previous information, implementing an energy management system is proposed, maintaining the characteristics of carrying out sampling at a one minute sampling period and minimizing energy consumption, which manages an inverse relationship concerning variance the error absolute value. 


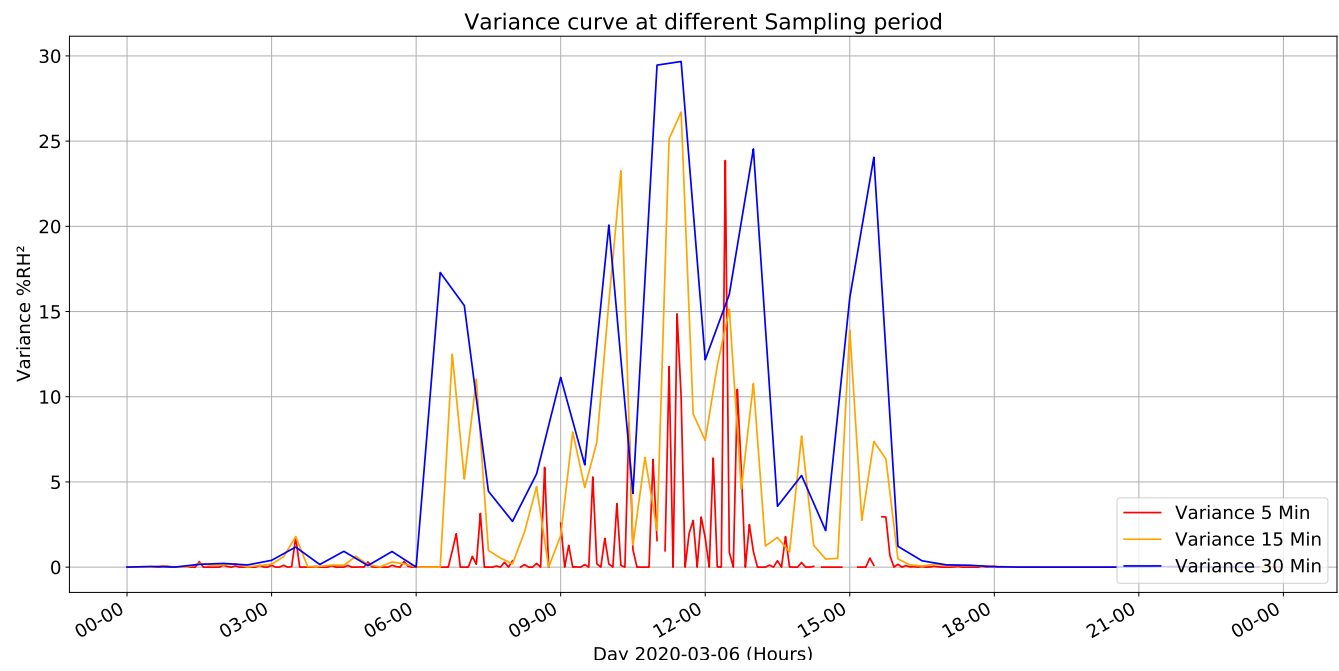

Figure 14. Humidity's variance for different sampling times.

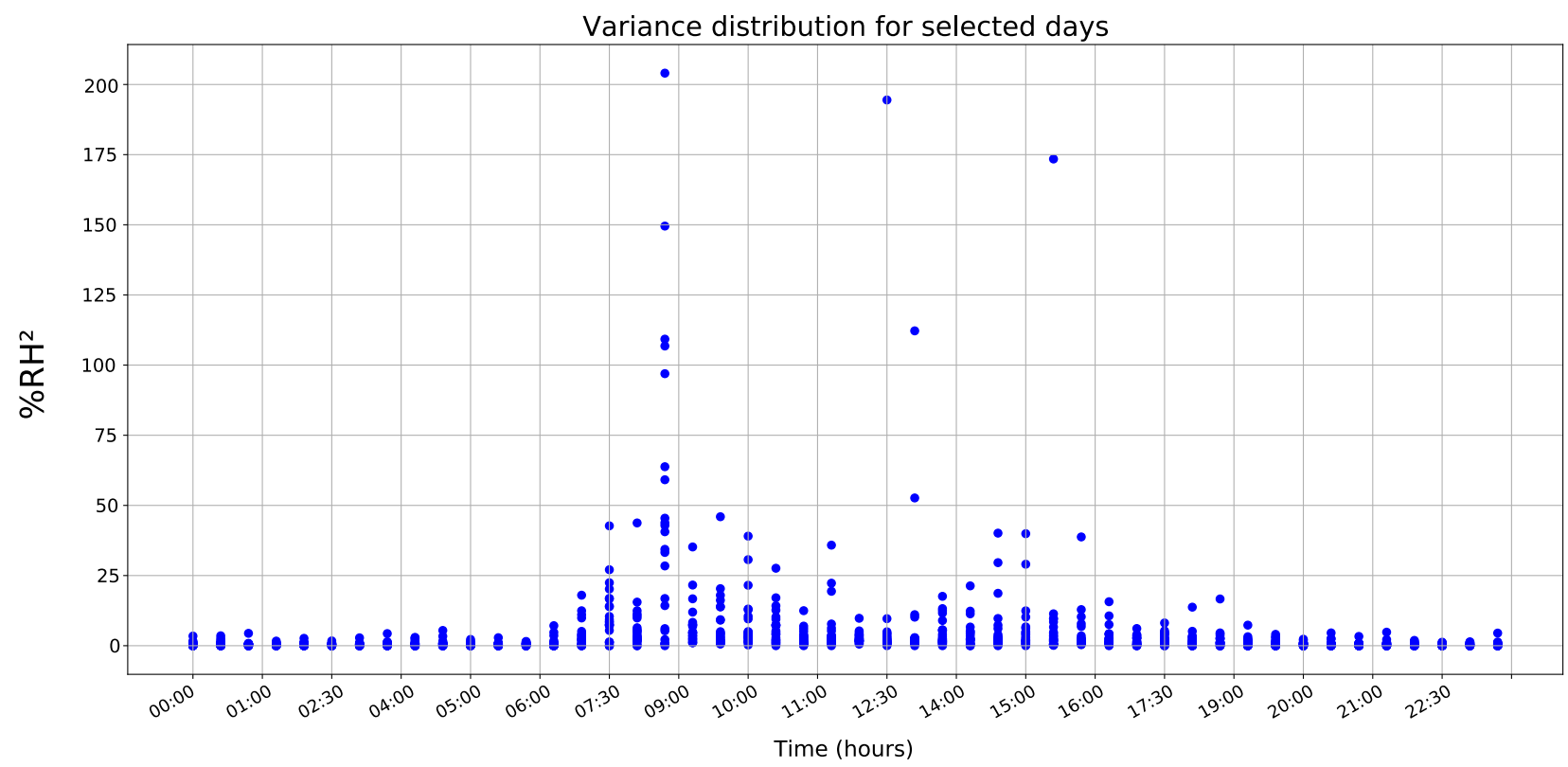

Figure 15. Variance behavior for all datasets.

\subsection{Stage III-Get Equation Values}

With selected variable's variance, this section found the best values for managing the device's energy consumption from a base equation.

Energy Management Equation

Equation (8) is proposed as a base point for our adaptive algorithm as the variance function and with two constants to find

$$
F s=\alpha * \operatorname{Var}(t)+\beta
$$

where:

$$
\begin{gathered}
F s \rightarrow \text { sampling frequency } \\
\operatorname{Var}(t) \rightarrow \text { Variance function } \\
\alpha, \beta \rightarrow \text { unknowns constants }
\end{gathered}
$$


Subject to the constraints:

$5.555 \times 10^{-3} \leq F s \leq 16.66 \times 10^{-3} \rightarrow$ sampling frequency range

Equation (8) is a base equation where the unknown variables are $\alpha$ and $\beta$ subject to a frequency range equivalent to a sampling period between $1 \mathrm{~min}$ and $30 \mathrm{~min}$ [45]. The period range is established based on consultation of interested experts to relate changes in humidity and temperature with studies related to production estimation, disease control, storage, transportation, which require a precise estimate of daily average maximum and minimum the variables selected values in this study [46-48].

Therefore, based on the equation result, sampling period (Ps) is established by the equation:

$$
P_{S}=\operatorname{round}\left(\frac{1}{60 * F s}\right)
$$

Equation (9) returns a value based on converting from frequency to time and rounding it to the nearest whole. This value is applied to the next sampling window (next $30 \mathrm{~min}$ ), where the error is calculated as energy consumption.

We selected two vectors and a day with high variance to define the $\alpha$ and $\beta$ values. $\alpha$ ranges from 0 to 0.1 with increments of $1 \times 10^{-3}$, and for $\beta$, a range from 0 to $10 \times 10^{-3}$ with an increment of $0.1 \times 10^{-3}$. It generates a two-dimensional matrix for each pair of $\alpha$ and $\beta$ values; thus, we have the error and energy consumption graph.

Figure 16a shows mean squared error (MSE) for different alpha and beta values. The highest error rates occur to values close to or equal to zero in alpha, related to handling fixed sampling time. Through the $\beta$ variation, it is possible to reduce error since it forces to have lower sampling periods to point that for values greater than $5 \times 10^{-3}$, the sampling is 1 min corresponding to minimum sampling period and consequently an error of zero.

Figure 16b shows current consumption for different alpha values and beta where a direct relationship is observed for parameters alpha, beta, and energy consumption; if fixed sampling intervals are selected $(\alpha=0)$, the lower current consumption values are obtained.

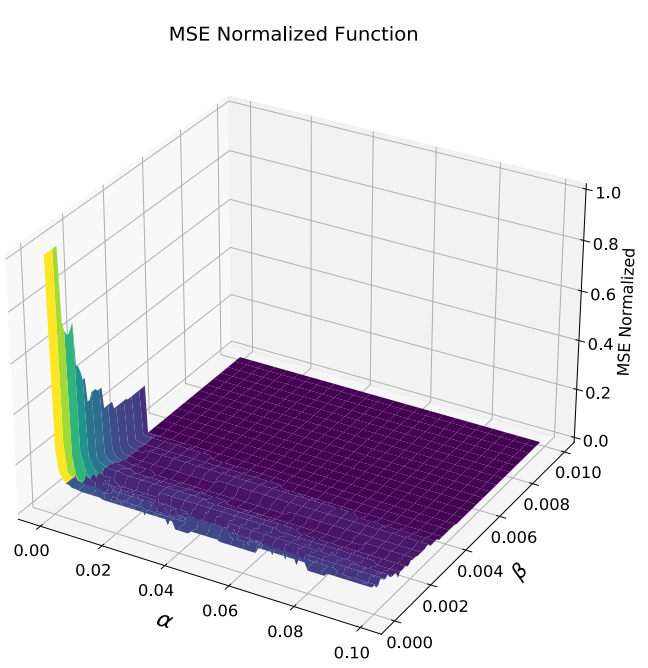

(a) MSE normalized

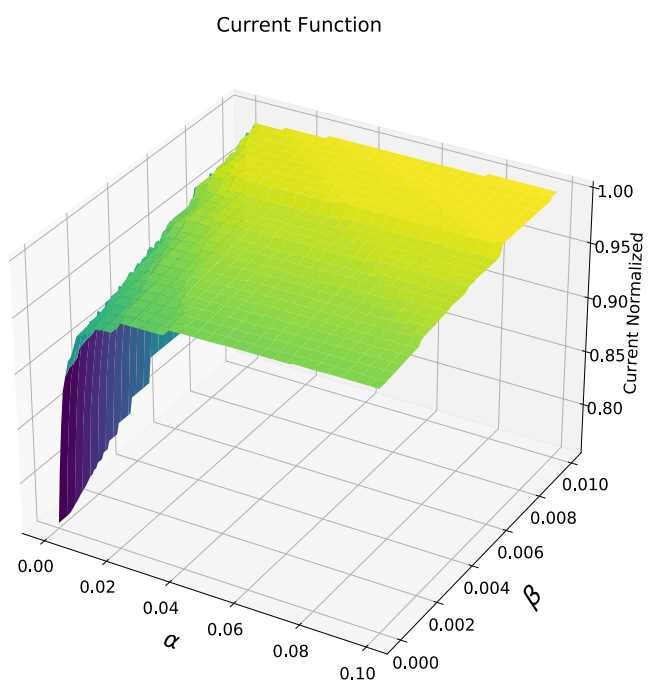

(b) Current normalized

Figure 16. MSE and Current normalized for different $\alpha$ and $\beta$.

For simplification purposes, we selected $\beta=0$ based on the previous graph due it represents the lowest current consumption curve. The equation is simplified to find a suitable alpha value because both error and current consumption are acceptable minimums. From the elimination of $\beta$, the error normalized curves and current consumption is in Figure 17. 
Figure 17 shows error(blue line), current consumption (red line), and sum of error and current consumption (green line) in the $\alpha$ function. Error and energy consumption are normalized because the contribution is proportional to the sum function. Due to high error values, the sum function shows a maximum alpha close to zero; and a stable value due to the current function. Likewise, we determined the value to reach the minimum, which corresponds to the lowest consumption under a low error and low current consumption (black vertical line).

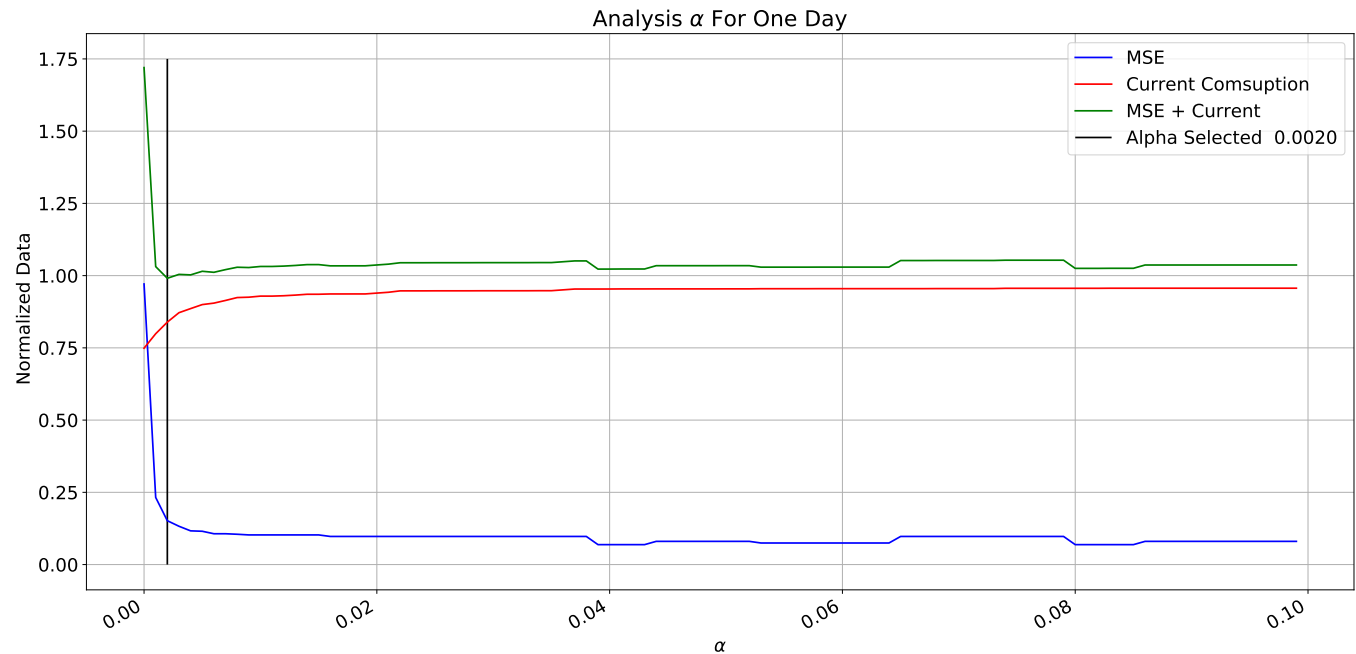

Figure 17. $\alpha$ analysis for one day.

We carried out the previous analysis for all selected days. Figure 18 shows MSE and current consumption; they had similar behavior, especially for MSE; current and MSE on Figure 18 are normalized, which generates the general function as shown in Figure 19, where the best $\alpha$ is selected for each day (black lines). As a result, a points distribution shows an alpha value between $2 \times 10^{-3}$ and $12 \times 10^{-3}$. We took the mean value for a general equation in the red line.

$\alpha$ vs Mean Squared Error for day
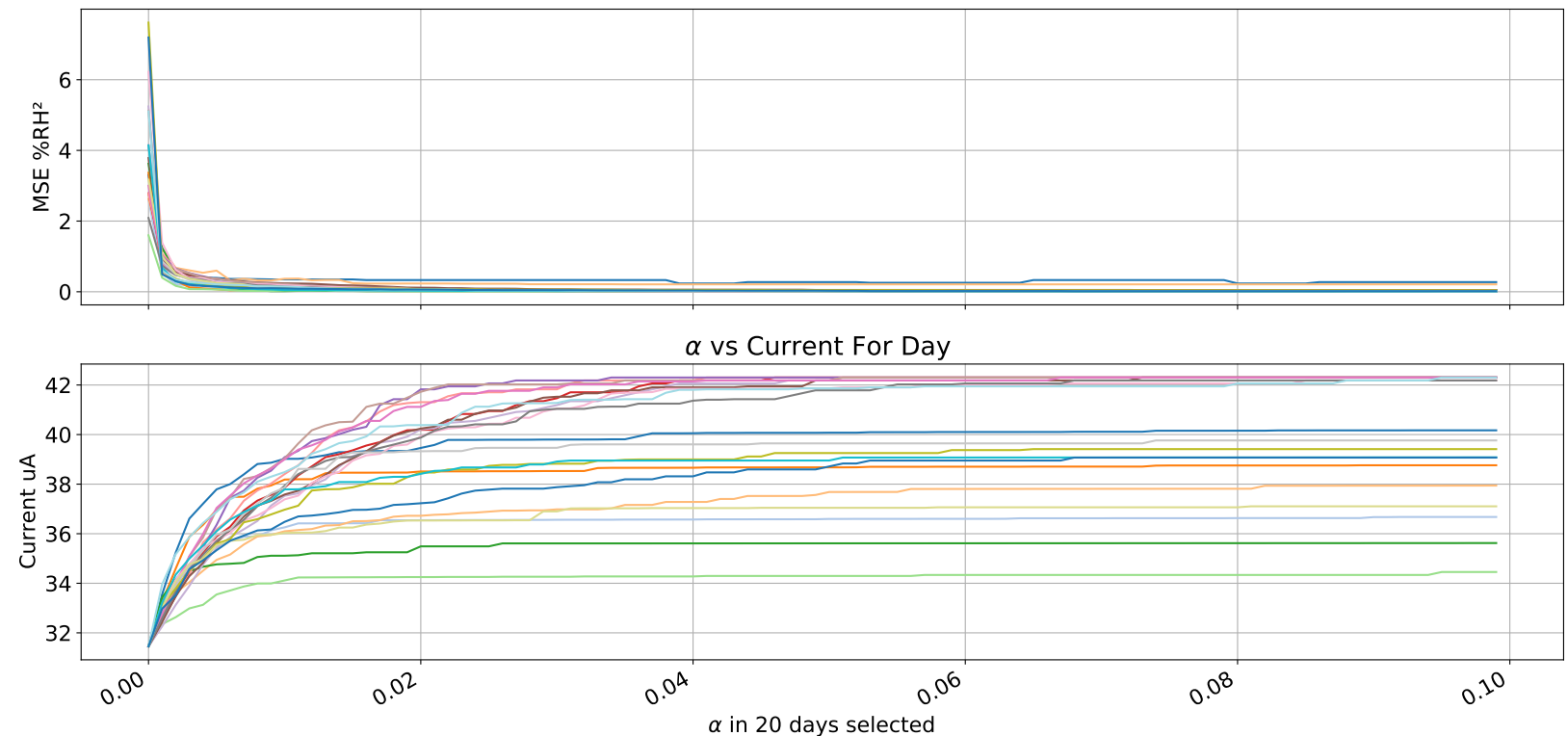

Figure 18. $\alpha$ analysis vs. Mean Squared Error and Current. 
$\alpha$ vs General Function For Day
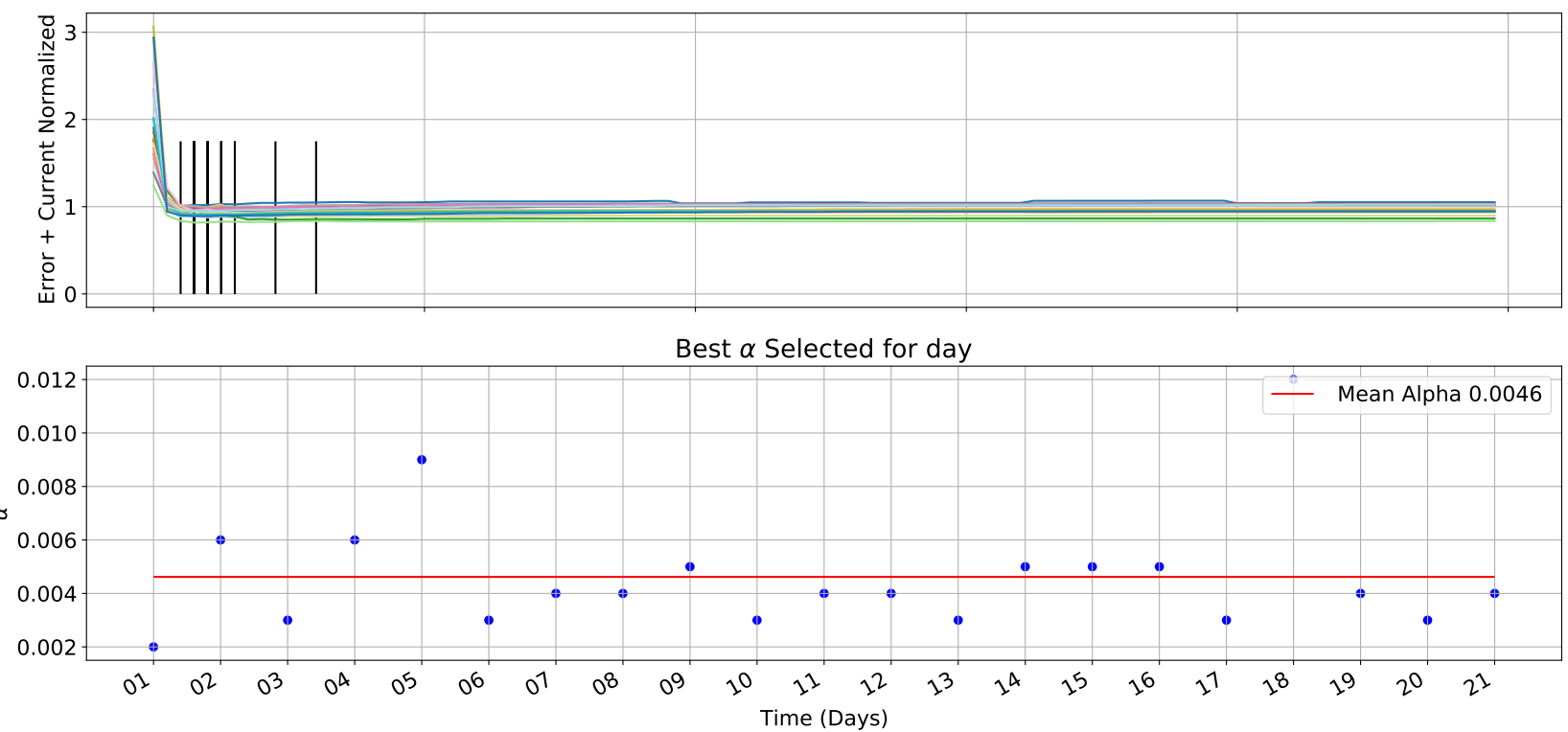

Figure 19. Best $\alpha$ analysis for day and mean $\alpha$.

Therefore, the equation is:

$$
\begin{gathered}
F s=4.6 \times 10^{-3} * \operatorname{Var}(t) \\
P S=\operatorname{round}\left(\frac{1}{60 *\left(4.6 \times 10^{-3} * \operatorname{Var}(t)\right)}\right)
\end{gathered}
$$

Finally, we have the next equation:

$$
\text { Ps }=\operatorname{round}\left(\frac{3.623}{\operatorname{Var}(t)}\right)
$$

Equation (12) defines transmission averaged variables period; it takes as a starting point the variance calculated in a 30 minute window and determines sending period. Ps can be between transmission every minute or a single one in $30 \mathrm{~min}$. Since variance calculation does not involve complex operations, as well as the equation found, can be programmed in the IoT devices firmware, equation does not represent a significant additional time.

\subsection{Evaluation}

To evaluate the equation, we installed two devices at each height of the tree and the evaluation was carried out in one plot, one with lowest sampling period (1 $\mathrm{min})$ and other with the equation's execution as a function of humidity variance. Figures 20 and 21 show results and demonstrate that our adaptive sampling method is working correctly (These measurements correspond to one day only apart from the whole data-set). 


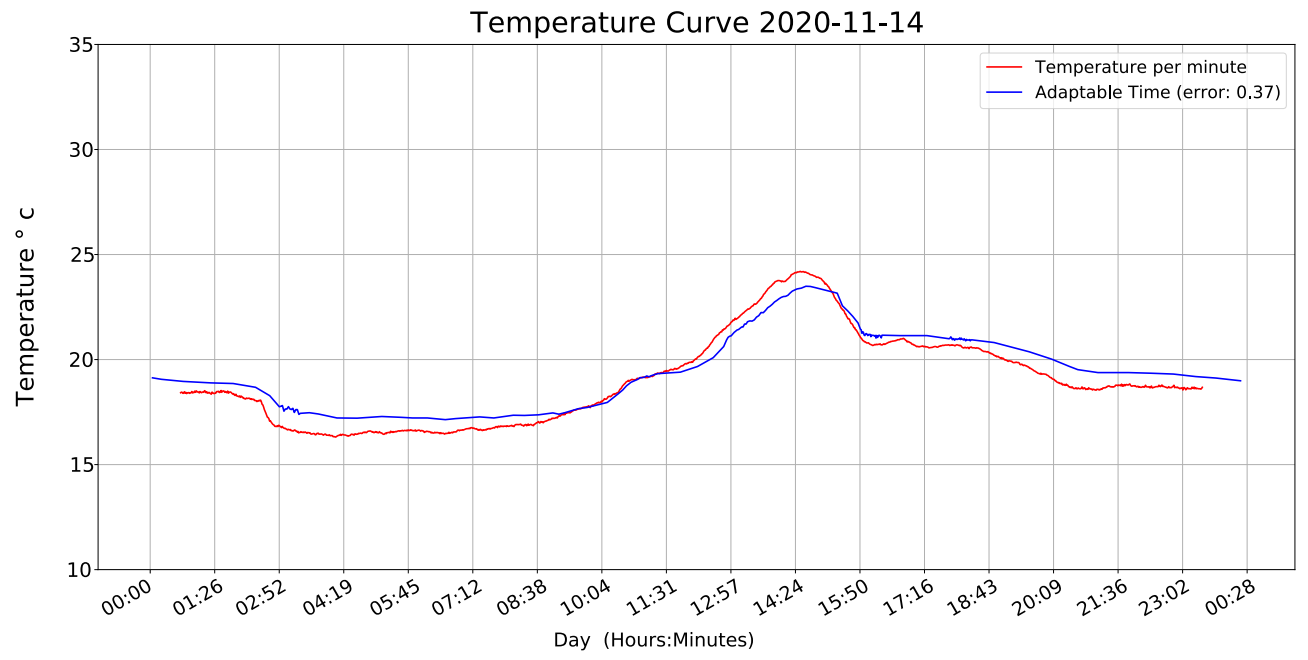

Figure 20. Temperature curve.

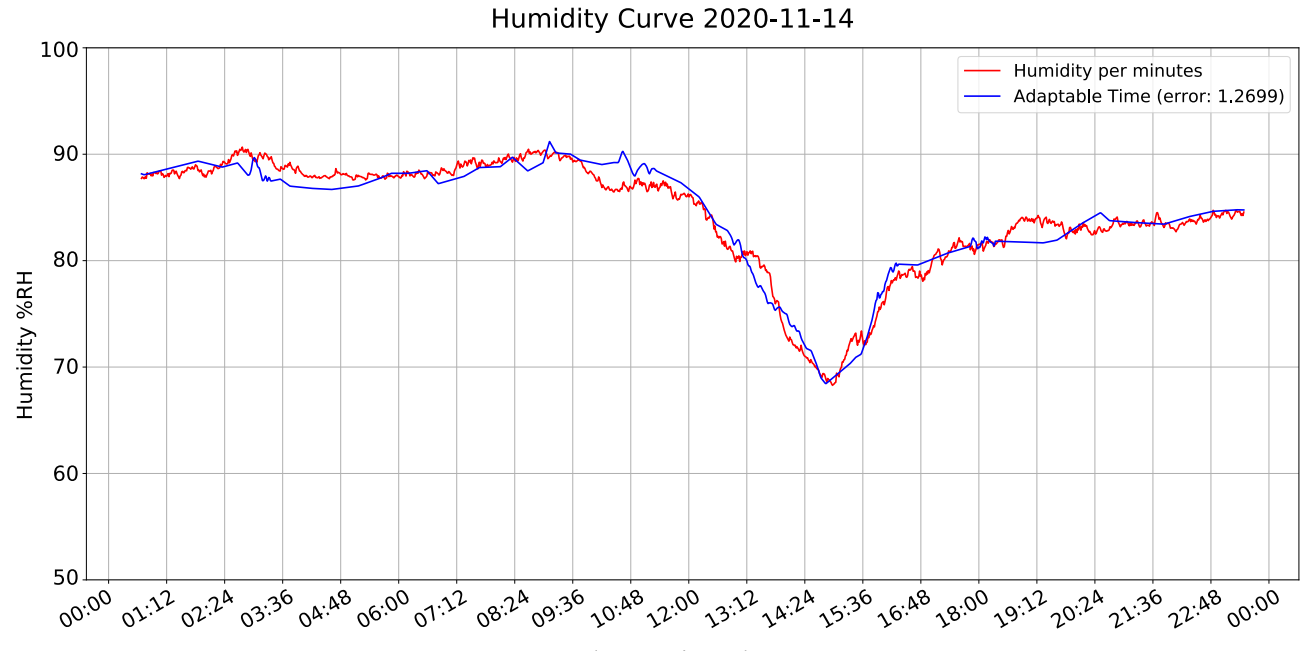

Figure 21. Humidity curve.

As shown in Figure 22, the IoT device sampling time is $30 \mathrm{~min}$ at starting point. The variance equation says humidity is changing, and the measure is updated $12 \mathrm{~min}$ after the first measurement window.

Figure 22 shows sampling intervals during measurements. If calculated variance increases, sampling interval becomes smaller. In other words, if there is a significant change in humidity, the IoT monitoring device measures the variables more often. This result proves that our code works fine, and our method can control the sampling period according to variable behavior.

We select a $30 \mathrm{~min}$ window because sensors have certain noises, especially humidity measurements, which are not negligible. Since our adaptive sampling method can be susceptible to the input values, noises can result in wrong sampling period adjustment, resulting in an energy loss. 


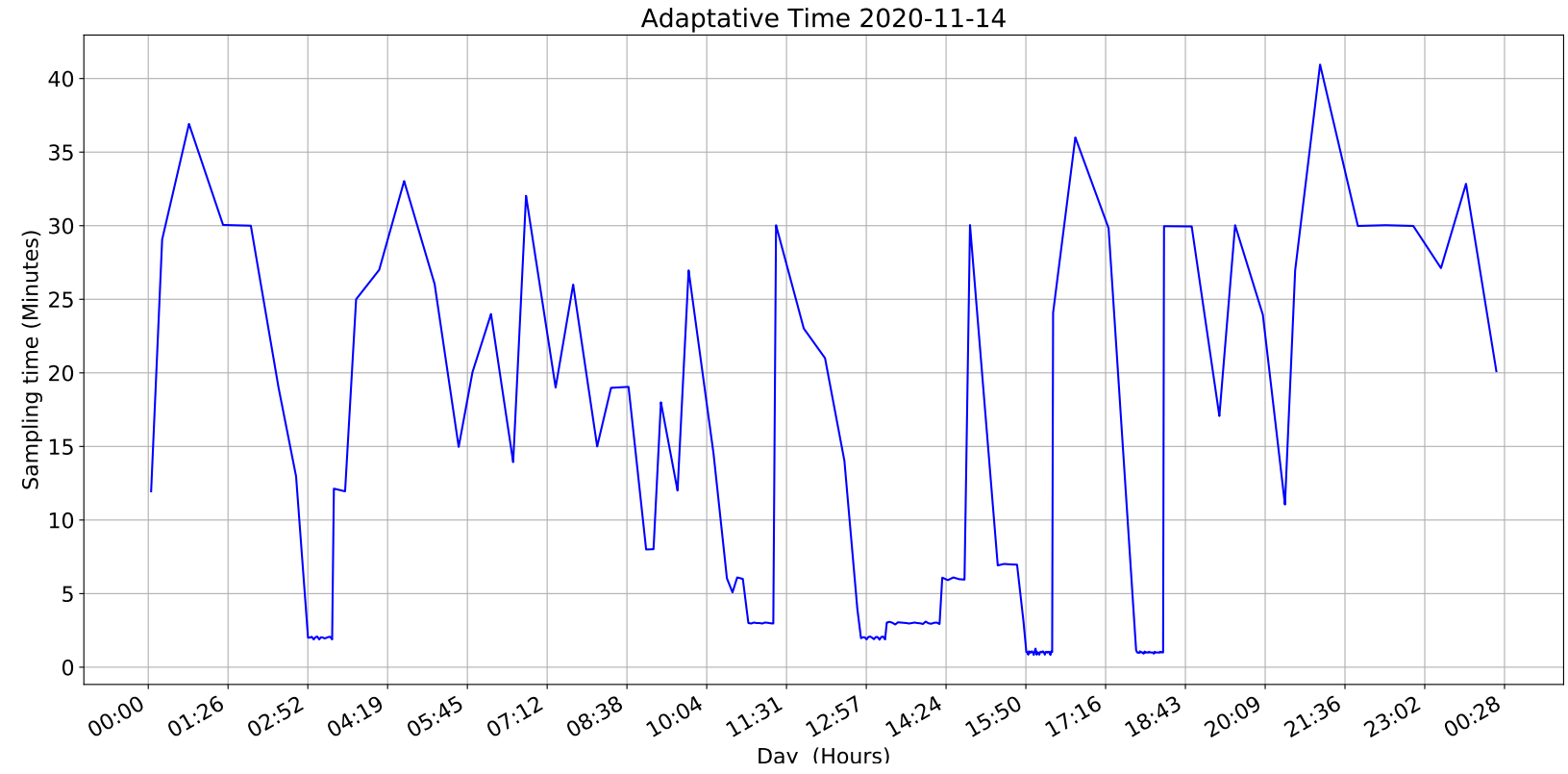

Figure 22. Adaptable time analysis.

\subsection{Performance Evaluation}

For environmental parameters performance evaluation, we used statistical metrics.

- $\quad$ Mean square error (MSE): defined previously in (7) and parameter base in this study. It can take any positive value with zero indicating a perfect lack of error;

- Mean absolute relative error (MARE): is defined as ratio of the measurement absolute error to the actual measurement. Relative error indicates how good measurement is relative to the object size being measured. If $x$ is the actual quantity value, $x 0$ is the quantity's measured value, and $\delta x$ is absolute error. The relative error is measured $(\delta x) / x$;

- Mean bias error (MBE): this measures the extent to which the estimated value deviates from observed value. It can take any value, with negative values indicating systematic under-estimation and positive values, over-estimation, and zero indicating a perfect lack of bias;

- Pearson's correlation coefficient (R) represents a linear dependence between two variables is widely used and easily interpreted, taking a value between $-1 \rightarrow 1$ with one indicating a perfect positive linear correlation [49];

- Nash-Sutcliffe efficiency coefficient (NSE): is a normalized indicator of model efficiency corresponding to the estimate's statistical agreement or skill relative to experimental measurements. It takes a value ranging from $-\infty \rightarrow 1.0$, with one being a perfect fit and negative values meaning that the station offers a better estimate.

Table 2 presents results for different metrics evaluated for energy system management. The temperature sensor presents better results than the humidity sensor because the first one has better accuracy $\left( \pm 0.2^{\circ} \mathrm{C}\right)$ than $( \pm 2 \% \mathrm{RH})$ humidity variable register. It was mainly reflected in MSE, which yielded results close to the sensor's accuracy, although a uniform environment for both devices.

Regarding MARE, the evaluation presents good results because, for this parameter, it considers the size or magnitude of the measured variable; therefore, the humidity values are more significant than temperature, the result yielded a smaller value. Concerning MBE related to a measurement error that remains constant in magnitude for all observations, it shows that temperature and humidity present values close to zero, indicating a pleasing lack of bias. For R, both variables have values close to 1 ; it indicates that a linear equation perfectly describes the relationship between variables sampled every minute and adaptive 
sampling. Subsequently, NSE represents that the sampling with adaptive function has a model with good predictive skill.

Above all, current consumption with adaptative sampling was equivalent to a fixed sampling of $8 \mathrm{~min}$, which, based on Figure 5, shows an almost flat part of the curve of device estimated life, this means the percentage decrease is very close to the maximal percentage decrease allowed.

Table 2. Statistics used for evaluation energy system management.

\begin{tabular}{lccc}
\hline \multicolumn{1}{c}{ Statistic } & Adaptative Time & Range & Ideal Value \\
\hline MSE Temperature & $0.369{ }^{\circ} \mathrm{C}^{2}$ & $0 \rightarrow \infty{ }^{\circ} \mathrm{C}^{2}$ & $0.0^{\circ} \mathrm{C}^{2}$ \\
\hline MSE Humidity & $1.28 \% R \mathrm{H}^{2}$ & $0 \rightarrow \infty \% R H^{2}$ & $0.0 \% R H^{2}$ \\
\hline MARE Temperature & 0.028 & $0 \rightarrow \infty$ & 0.0 \\
\hline MARE humidity & 0.011 & $0 \rightarrow \infty$ & 0.0 \\
\hline MBE Temperature & 0.345 & $-\infty \rightarrow \infty$ & 0.0 \\
\hline MBE humidity & 0.0015 & $-\infty \rightarrow \infty$ & 0.0 \\
\hline R Temperature & 0.979 & $-1.0 \rightarrow 1.0$ & 1.0 \\
\hline R Humidity & 0.977 & $-1.0 \rightarrow 1.0$ & 1.0 \\
\hline NSE temperature & 0.917 & $-\infty \rightarrow 1.0$ & 1.0 \\
\hline NSE humidity & 0.954 & $-\infty \rightarrow 1.0$ & 1.0 \\
\hline Current Consumption & $34.92 \mu \mathrm{A}$ & $34.47 \mu \mathrm{A} \rightarrow$ & $34.47 \mu \mathrm{A}$ \\
\hline$\%$ Current Consumption Decrease & $11.04 \%$ & $0 \% \rightarrow 12.2 \%$ & $12.2 \%$ \\
\hline
\end{tabular}

Figure 23 illustrates results obtained under different climatic conditions. There is a more significant variation in temperature and humidity on sunny days; devices adjust to a sampling period of one minute longer than rainy days. The above allows us to evaluate the $\alpha$ parameter behavior and the proposed management system from a lower level of variation in temperature and humidity and more extended sampling periods. We conducted this experiment on conditions presented on different outdoor days where climate variability is more significant than warehouses or transport vehicles.
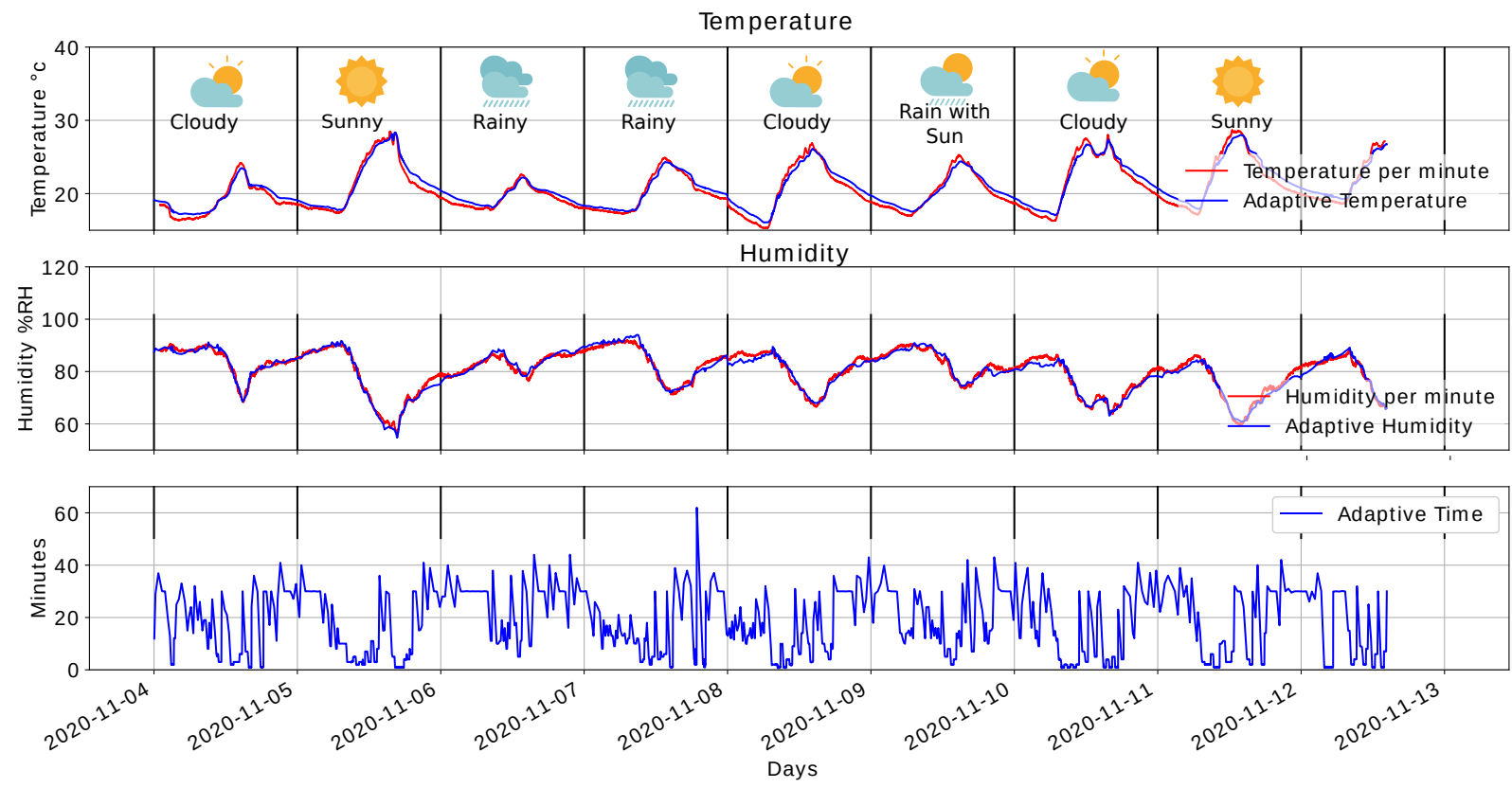

Figure 23. Result for different day conditions. 
Finally, Table 3 presents different metrics evaluated for days under different climatic conditions. The results are the approach of the worse scenario, where the system is implemented. The metrics do not present a significant difference concerning selected day analysis that presented great variation. The energy savings compared to the one day analysis decreased by $0.16 \%$.

Table 3. Resume Statics for days with different conditions.

\begin{tabular}{lccc}
\hline \multicolumn{1}{c}{ Statics } & Adaptative Time & Range & Ideal Value \\
\hline MSE Temperature & $0.476{ }^{\circ} \mathrm{C}^{2}$ & $0 \rightarrow \infty{ }^{\circ} \mathrm{C}^{2}$ & $0.0{ }^{\circ} \mathrm{C}^{2}$ \\
\hline MSE Humidity & $2.33 \% R H^{2}$ & $0 \rightarrow \infty \% R H^{2}$ & $0.0 \% R H^{2}$ \\
\hline MARE Temperature & 0.030 & $0 \rightarrow \infty$ & 0.0 \\
\hline MARE humidity & 0.015 & $0 \rightarrow \infty$ & 0.0 \\
\hline MBE Temperature & 0.302 & $-\infty \rightarrow \infty$ & 0.0 \\
\hline MBE humidity & -0.25 & $-\infty \rightarrow \infty$ & 0.0 \\
\hline R Temperature & 0.983 & $-1.0 \rightarrow 1.0$ & 1.0 \\
\hline R Humidity & 0.981 & $-1.0 \rightarrow 1.0$ & 1.0 \\
\hline NSE temperature & 0.9498 & $-\infty \rightarrow 1.0$ & 1.0 \\
\hline NSE humidity & 0.959 & $-\infty \rightarrow 1.0$ & 1.0 \\
\hline Current Consumption & $34.99 \mu \mathrm{A}$ & $34.47 \mu \mathrm{A} \rightarrow$ & $34.47 \mu \mathrm{A}$ \\
\hline$\%$ Current Consumption Decrease & $10.88 \%$ & $0 \% \rightarrow 12.2 \%$ & $12.2 \%$ \\
\hline
\end{tabular}

\section{Discussion}

This section discusses energy consumption management performance compared to results obtained in other proposed models. In summary, adaptive solutions evaluation is mainly compared with fixed sampling schemes, where consumption savings and data quality are primarily considered. In [22], the study selects a suitable sampling frequency during the acquisition process according to signal frequency's spectral content. This paper obtained energy savings between $44 \%$ and $72 \%$, and MSE values between $1.3 \times 10^{-4}$ and $1.5 \times 10^{-2}$ for three evaluated signals. Similarly, in [23], the study performs a frequency analysis, mainly through a fast Fourier transform. They found that the algorithm can reduce the number of acquired samples up to $79 \%$ concerning fixed sampling frequency. At the same time, generally, mean absolute error (MAE) shows a preservation of the data accuracy. In [20], the study shows a model based on the sensing-driven cluster, correlationbased sampler selection and model derivation and adaptive data collection, and modelbased prediction called ASAP. This was compared by introducing two ASAP variants: local approach and central approach under a set of experiments study the performance concerning messaging cost, energy consumption perspective, and the collected data quality. In [26], different aspects were evaluated to highlight their methods conserved energy by $29 \%, 47 \%$, and $25 \%$, respectively. The last paper has a close proposal since one of the proposed algorithms considers variance; however, the proposed similarity algorithm is different from the strategy proposed in our article.

Our proposal evaluated different metrics by capturing real data, evidencing good results in terms of data quality, such as MSE, MAE, and Pearson correlation. However, it is essential to highlight the effect of variables such as the devices accuracy and sensitivity used. Regarding energy-saving terms, on average, it was a $10.88 \%$ significantly low value compared to other related works; however, it corresponds to a value of $89 \%$ within the range of possible reduction for the IoT device. 


\section{Conclusions and Future Work}

We proposed the adaptive sampling period method to keep the IoT device current consumption to a minimum and maintain the outstanding sensing quality based on MSE of variables, especially for humidity monitoring. We found a specific variance pattern in the everyday humidity and temperature measurements in which humidity is more significant than temperature. It let us reduce transmission, which is a big part of energy consumption on IoT devices. We decided that an adaptive sampling method is appropriate to achieve our goal and develop a technique to adapt the sampling interval of devices based on the variables' variance, which is a dispersion measure between values in environmental variables.

We simulated the method with Python taking into account a minute-by-minute measured dataset. The outcome proves that an adaptive sampling method decreases transmissions significantly while providing acceptable quality measurements. Finally, we tested our method with real sensors used in the IoT-Agro project, demonstrating the effectiveness and flexibility.

We evaluated the proposed management systems indoors and outdoors; we located two devices, one with sampling every minute and the other with the adaptive system. For temperature evaluation, the mean square error (MSE) was $0.369^{\circ} \mathrm{C}^{2}$, a value close to $0.2^{\circ} \mathrm{C}$ the accuracy of the sensor; in Pearson's correlation, the results were above 0.97, in mean absolute relative error (MARE) presented values lower than 0.028.

For humidity, we obtained an error more significant than expected. Despite generating conditions similar to the two devices, the sensor's accuracy means that two sensors do not deliver the same value under the same conditions. Therefore, the mean square error (MSE) was $1.39 \% \mathrm{RH}$, a value lower than $2 \% \mathrm{RH}$ to the sensor's accuracy. In terms of Pearson's correlation, the results gave values above 0.97 , in the mean absolute relative error (MARE) presented values lower than 0.03 . With the advantages of adaptive sampling, we achieved an equivalent to an 8 minute sampling in terms of current consumption. The lowest admissible sample corresponds to a minute in the hours with a more significant variation.

With the proposed management system, a reduction of $11.04 \%$ is achieved; the result is significant because the maximum possible percentage is $12.2 \%$, equivalent to performing sampling every $30 \mathrm{~min}$ all the time. The reduction percentage was $90 \%$ for the selected day and $89.18 \%$ for the selected group of days with different weather conditions concerning the total percentage decrease allowed.

Our adaptive sampling method determines the next sampling period based on the variance of the previous measurements. Thus, if there is considerable noise, it will not affect the result, and since the method has a $30 \mathrm{~min}$ window is not very sensitive to a slight change of the measurements; therefore, we can handle the noise. This document shows the best values for $\alpha$ and $\beta$ by simulations with the humidity variable. However, the target variable can be determined by $\alpha$ and $\beta$ are user parameters.

From work carried out, opportunities open up to continue improving the proposed energy management system; some current challenges are: To obtain feedback from the system through a forecasting service to fine-tune the selected $\alpha$ parameter; To work in a controlled environment to generate equal conditions for the sensors, obtain good evaluations of developed systems, and perform system evaluations for extended periods to detect faults.

Author Contributions: C.R.-P., J.R.-R. and G.R.-G.; contributed to the design and implementation of the research, C.R-P., J.R.-R. and G.R.-G.; Software, C.R.-P., G.R. and C.Z.; Validation, C.R.-P., J.R.-R., J.C.C. and G.R.-G.; Formal analysis, C.R.-P.; Investigation, C.R.-P., G.R., C.Z. and J.C.C.; Resources, C.R.-P., J.R.-R. and G.R.-G.; Data curation, C.R.-P.; Writing-original draft preparation, C.R.-P., J.R.-R., G.R., C.Z. and G.R.-G.; Writing-review and editing, C.R.-P., J.R.-R., G.R. and G.R.-G.; Visualization, C.R.-P.; Supervision, J.R.-R., J.C.C. and G.R.-G.; Project administration, G.R.-G.; and Funding acquisition, G.R.-G. and J.C.C. All authors have read and agreed to the published version of the manuscript.

Funding: This work was funded by the Universidad del Cauca (501100005682). 


\section{Institutional Review Board Statement: Not applicable.}

Informed Consent Statement: Not applicable.

Data Availability Statement: Not applicable.

Acknowledgments: The authors wish to thank the University of Cauca, the Telematic Engineering research Group (GIT), the project called "Estrategias para la valorización de los dulces tradicionales de Popayán, Financiado por la convocatoria 808-2018 del Ministerio de Ciencia, Tecnología e Innovación de Colombia (Minciencias), mediante contrato 80740-127-2019". The author thanks National Technological University-Córdoba Argentina Regional School (UTN- FRC.)

Conflicts of Interest: The authors declare no conflict of interest.

\section{References}

1. Morillo, P.; Orduña, J.M.; Fernández, M.; García-Pereira, I. Comparison of WSN and IoT approaches for a real-time monitoring system of meal distribution trolleys: A case study. Future Gener. Comput. Syst. 2018, 87, 242-250. [CrossRef]

2. Saville, R.; Hatanaka, K.; Wada, M. ICT application of real-time monitoring and estimation system for set-net fishery. In Proceedings of the OCEANS 2015-MTS/IEEE Washington, Washington, DC, USA, 19-22 October 2015; pp. 1-5. [CrossRef]

3. Mabrouki, J.; Azrour, M.; Dhiba, D.; Farhaoui, Y.; Hajjaji, S.E. IoT-based data logger for weather monitoring using arduino-based wireless sensor networks with remote graphical application and alerts. Big Data Min. Anal. 2021, 4, 25-32. [CrossRef]

4. $\quad$ Liu, Y.; Li, D.; Wan, S.; Wang, F.; Dou, W.; Xu, X.; Li, S.; Ma, R.; Qi, L. A long short-term memory-based model for greenhouse climate prediction. Int. J. Intell. Syst. 2022, 37, 135-151. [CrossRef]

5. Čolaković, A.; Hadžialić, M. Internet of Things (IoT): A review of enabling technologies, challenges, and open research issues. Comput. Netw. 2018, 144, 17-39. [CrossRef]

6. Ray, P.P. Internet of things for smart agriculture: Technologies, practices and future direction. J. Ambient. Intell. Smart Environ. 2017, 9, 395-420. [CrossRef]

7. Elijah, O.; Rahman, T.A.; Orikumhi, I.; Leow, C.Y.; Hindia, M.N. An Overview of Internet of Things (IoT) and Data Analytics in Agriculture: Benefits and Challenges. IEEE Internet Things J. 2018, 5, 3758-3773. [CrossRef]

8. Azrour, M.; Mabrouki, J.; Guezzaz, A.; Farhaoui, Y. New enhanced authentication protocol for Internet of Things. Big Data Min. Anal. 2021, 4, 1-9. [CrossRef]

9. Federacion Nacional de Cafeteros. FAQ's Logistica / Federación Nacional de Cafeteros. Available online: https://www. federaciondecafeteros.org/clientes/es/faqs/logistica/ (accessed on 29 March 2019).

10. Jawad, H.M.; Nordin, R.; Gharghan, S.K.; Jawad, A.M.; Ismail, M.; Abu-Alshaeer, M.J. Power reduction with sleep/wake on redundant data (SWORD) in a wireless sensor network for energy-efficient precision agriculture. Sensors 2018, 18, 3450. [CrossRef]

11. Jin, W.; Kim, D. A sleep-awake scheme based on coap for energy-efficiency in internet of things. Int. J. Inform. Vis. 2017, 1, 110-114. [CrossRef]

12. Jain, A.; Chang, E.Y. Adaptive sampling for sensor networks. ACM Int. Conf. Proc. Ser. 2004, 72, 10-16. [CrossRef]

13. Li, J.; Vera, A.M.; Sai, V.; Cheng, X.; Cheng, W.; Tian, Z.; Li, Y. Sampling-Based Approximate Skyline Query in Sensor Equipped IoT Networks. 2021, 26, 219-229. [CrossRef]

14. Nowak, R.; Mitra, U. Boundary Estimation in Sensor Networks: Theory and Methods. In Information Processing in Sensor Networks; Zhao, F., Guibas, L., Eds.; Springer: Berlin/Heidelberg, Germany, 2003; pp. 80-95.

15. Rani, S.; Talwar, R.; Malhotra, J.; Ahmed, S.H.; Sarkar, M.; Song, H. A Novel Scheme for an Energy Efficient Internet of Things Based on Wireless Sensor Networks. Sensors 2015, 15, 28603-28626. [CrossRef] [PubMed]

16. Safara, F.; Souri, A.; Baker, T.; Al Ridhawi, I.; Aloqaily, M. PriNergy: A priority-based energy-efficient routing method for IoT systems. J. Supercomput. 2020, 76, 8609-8626. [CrossRef]

17. Yitayal, E.; Pierson, J.M.; Ejigu, D. A balanced battery usage routing protocol to maximize network lifetime of MANET based on AODV. In NEW2AN 2014: Internet of Things, Smart Spaces, and Next Generation Networks and Systems; International Conference on Next Generation Wired/Wireless Networking; Springer: Berlin/Heidelberg, Germany, 2014; Volume 8638, pp. 266-279. [CrossRef]

18. Devi, M.D.; Geetha, K.; Saranyadevi, K. Content Based Routing Using Information Centric Network For IoT. In Proceedings of the 7th International Conference on Advances in Computing and Communications (ICACC), Kochin, India, 22-24 August 2017; Volume 115, pp. 707-714. [CrossRef]

19. Silva, J.M.C.; Bispo, K.A.; Carvalho, P.; Lima, S.R. LiteSense: An adaptive sensing scheme for WSNs. In Proceedings of the 2017 IEEE Symposium on Computers and Communications (ISCC), Heraklion, Greece, 3-6 July 2017; pp. 1209-1212. [CrossRef]

20. Gedik, B.; Liu, L.; Yu, P.S. ASAP: An adaptive sampling approach to data collection in sensor networks. IEEE Trans. Parallel Distrib. Syst. 2007, 18, 1766-1783. [CrossRef]

21. Tayeh, G.B.; Makhoul, A.; Laiymani, D.; Demerjian, J. A distributed real-time data prediction and adaptive sensing approach for wireless sensor networks. Pervasive Mob. Comput. 2018, 49, 62-75. [CrossRef] 
22. Kurp, T.; Gao, R.X.; Sah, S. An adaptive sampling scheme for improved energy utilization in wireless sensor networks. In Proceedings of the 2010 IEEE International Instrumentation and Measurement Technology Conference, Austin, TX, USA, 3-6 May 2010; pp. 93-98. [CrossRef]

23. Alippi, C.; Anastasi, G.; Di Francesco, M.; Roveri, M. An adaptive sampling algorithm for effective energy management in wireless sensor networks with energy-hungry sensors. IEEE Trans. Instrum. Meas. 2010, 59, 335-344. [CrossRef]

24. Gupta, V.; De, S. SBL-Based Adaptive Sensing Framework for WSN-Assisted IoT Applications. IEEE Internet Things J. 2018, 5, 4598-4612. [CrossRef]

25. Hao, J.; Zhang, B.; Jiao, Z.; Mao, S. Adaptive compressive sensing based sample scheduling mechanism for wireless sensor networks. Pervasive Mob. Comput. 2015, 22, 113-125. [CrossRef]

26. Harb, H.; Makhoul, A. Energy-efficient sensor data collection approach for industrial process monitoring. IEEE Trans. Ind. Inform. 2017, 14, 661-672. [CrossRef]

27. Ceballos, F.; Robles, M. Weather Risks and Insurance Opportunities for the Rural Poor. In Resilience for Food and Nutrition Security International Food Policy Research Institute: Washington, DC, USA, 2014; pp. 83-90.

28. Zhao, J.C.; Zhang, J.F.; Feng, Y.; Guo, J.X. The study and application of the IOT technology in agriculture. In Proceedings of the 2010 3rd IEEE International Conference on Computer Science and Information Technology, Chengdu, China, 9-11 July 2010; pp. 462-465. [CrossRef]

29. Paull, R.E. Effect of temperature and relative humidity on fresh commodity quality. Postharvest Biol. Technol. 1999, 15, 263-277. [CrossRef]

30. Perakis, K.; Lampathaki, F.; Nikas, K.; Georgiou, Y.; Marko, O.; Maselyne, J. CYBELE - Fostering precision agriculture \& livestock farming through secure access to large-scale HPC enabled virtual industrial experimentation environments fostering scalable big data analytics. Comput. Netw. 2020, 168, 107035. [CrossRef]

31. James, C. Food Transportation and Refrigeration Technologies-Design and Optimization; Elsevier: Amsterdam, The Netherlands, 2019; pp. 185-199. [CrossRef]

32. Piergiovanni, L.; Limbo, S. Food Shelf-Life Models; Elsevier: Amsterdam, The Netherlands, 2019; pp. 49-60. [CrossRef]

33. Bradford, K.J.; Dahal, P.; Van Asbrouck, J.; Kunusoth, K.; Bello, P.; Thompson, J.; Wu, F. The dry chain: Reducing postharvest losses and improving food safety in humid climates. Trends Food Sci. Technol. 2018, 71, 84-93. [CrossRef]

34. Bhatnagar, A.; Vrat, P.; Shankar, R. Multi-criteria clustering analytics for agro-based perishables in cold-chain. J. Adv. Manag. Res. 2019, 16. [CrossRef]

35. Behdani, B.; Fan, Y.; Bleomhof, J. Cool Chain and Temperature-Controlled Transport: An Overview of Concepts, Challenges and Technologies. SSRN Electron. J. 2018. [CrossRef]

36. Akkerman, R. Sustainable Food Processing: A Production Planning and Scheduling Perspective; Elsevier: Amsterdam, The Netherlands, 2019; pp. 105-114. [CrossRef]

37. Baruffaldi, G.; Accorsi, R.; Santi, D.; Manzini, R.; Pilati, F. The Storage of Perishable Products: A Decision-Support Tool to Manage Temperature-Sensitive Products Warehouses; Elsevier: Amsterdam, The Netherlands, 2019; pp. 131-143. [CrossRef]

38. Grimaud, P.; Sserunjogi, M.; Wesuta, M.; Grillet, N.; Kato, M.; Faye, B. Effects of season and agro-ecological zone on the microbial quality of raw milk along the various levels of the value chain in Uganda. Trop. Anim. Health Prod. 2009, 41, 883-890. [CrossRef]

39. ELITEGROUP, E. CSCG Tag I ECS Global. Available online: https://www.ecs.com.tw/en/Product/IoT/CSCG_Tag/overview (accessed on 10 February 2021).

40. Rodríguez, J.P.; Montoya-Munoz, A.I.; Rodriguez-Pabon, C.; Hoyos, J.; Corrales, J.C. IoT-Agro: A smart farming system to Colombian coffee farms. Comput. Electron. Agric. 2021, 190, 106442. [CrossRef]

41. Fourati, L.; Kamoun, L. Performance Analysis of IEEE 802.15.4/Zigbee Standard Under Real Time Constraints. Int. J. Comput. Netw. Commun. 2011, 315. [CrossRef]

42. Otii Arc. Available online: https://www.qoitech.com/otii/ (accessed on 10 October 2021)

43. Supracafé Beyond a Cup of Coffee. Available online: https://www.supracafe.com/ (accessed on 10 August 2021).

44. BPMN-Coffee-Model. Available online: https://github.com/iotagro2018/BPMN-coffee-model (accessed on 10 October 2021).

45. ASABE. Measurement and Reporting Practices for Automatic Agricultural Weather Stations. 2015; p. 1. Available online: https: / / elibrary.asabe.org/abstract.asp?aid=45472\&t=2 (accessed on 10 August 2021).

46. DaMatta, F.M.; Cochicho Ramalho, J.D. Impacts of drought and temperature stress on coffee physiology and production: A review. Braz. J. Plant Physiol. 2006, 18, 55-81. [CrossRef]

47. Kath, J.; Byrareddy, V.M.; Craparo, A.; Nguyen-Huy, T.; Mushtaq, S.; Cao, L.; Bossolasco, L. Not so robust: Robusta coffee production is highly sensitive to temperature. Glob. Chang. Biol. 2020, 26, 3677-3688. [CrossRef]

48. Kath, J.; Mittahalli Byrareddy, V.; Mushtaq, S.; Craparo, A.; Porcel, M. Temperature and rainfall impacts on robusta coffee bean characteristics. Clim. Risk Manag. 2021, 32, 100281. [CrossRef]

49. Weisstein, E.W. Correlation Coefficient. Available online: https://mathworld.wolfram.com/CorrelationCoefficient.html (accessed on 11 November 2021). 